\title{
Filaggrin deficient mice have a lower threshold for cutaneous allergen sensitization but do not develop spontaneous skin inflammation or atopy
}

Lina Muhandes ${ }^{1}$, Martin Pippel ${ }^{2}$, Maria Chapsa ${ }^{3}$, Rayk Behrendt ${ }^{1}$, Yan $\mathrm{Ge}^{1}$, Andreas Dahl ${ }^{4}$, Buqing $\mathrm{Yi}^{5}$, Alexander Dalpke ${ }^{5}$, Sylke Winkler ${ }^{2}$, Michael Hiller ${ }^{2}$, Stefan Beissert ${ }^{3}$, Rolf Jessberger ${ }^{6}$, Padraic G. Fallon ${ }^{7}$, Axel Roers ${ }^{1}$

${ }^{1}$ Institute for Immunology, Medical Faculty Carl Gustav Carus, University of Technology Dresden, Dresden, Germany

${ }^{2}$ Max Planck Institute of Molecular Cell Biology and Genetics, Dresden, Germany

${ }^{3}$ Department of Dermatology, University Hospital Carl Gustav Carus, Technical University of Dresden, Dresden, Germany

${ }^{4}$ Center for Regenerative Therapies Dresden, Dresden, Germany

${ }^{5}$ Institute of Medical Microbiology and Hygiene, Medical Faculty Carl Gustav Carus,

Technische Universität Dresden, Dresden, Germany

${ }^{6}$ Institute of Physiological Chemistry, Medical Faculty Carl Gustav Carus, Technische Universität Dresden, Dresden, Germany

${ }^{7}$ School of Medicine, Trinity Biomedical Sciences Institute, Trinity College Dublin, Dublin, Ireland

\begin{abstract}
Defects of filaggrin (FLG) compromise epidermal barrier function and represent an important known genetic risk factor for atopic dermatitis (AD), but also for systemic atopy, including allergic sensitization and asthma. The flaky tail mouse model, widely used to address mechanisms of atopy induction by barrier-defective skin, harbors two mutations that affect the skin barrier, the mutation $\mathrm{Flg}^{f t}$, resulting in near-complete loss of FLG expression, and the matted mutation inactivating transmembrane protein 79 (Tmem79). Upon separation of the two mutant loci, which are closely linked on chromosome 3, mice defective only for Tmem79 featured pronounced dermatitis and systemic atopy. Upon extensive backcross to $\mathrm{BALB} / \mathrm{C}$, also $\mathrm{Flg}^{\mathrm{ft} / \mathrm{ft}}$ mice (assumed to be wild type for Tmem79), developed AD-like dermatitis and reproduced the human 'atopic march', with high IgE levels and spontaneous asthma, suggesting a key role for functional Flg in protection from atopy also in mice. In contrast, BALB/C mice congenic for a targeted Flg knock out mutation did not develop skin inflammation or atopy. To resolve this discrepancy, we generated Flg-deficient mice on a pure BALB/C background by inactivating the $\mathrm{Flg}$ gene in BALB/C embryos. These animals feature an ichthyosis phenotype, but do not develop spontaneous dermatitis or systemic atopy. We sequenced the genome of the atopic $F / g^{f t}$ BALB/C congenics and discovered that they were unexpectedly homozygous for the atopy-causing Tmem $79^{\text {matted }}$ mutation. In summary, we show that Flg-deficiency does not cause atopy in mice. This finding is in line with lack of atopic disease in a fraction of Ichthyosis vulgaris patients carrying two FLG null alleles. However, absence of FLG may promote and modulate dermatitis caused by other genetic barrier defects, as skin inflammation in $T m e m 79^{\mathrm{ma} / \mathrm{ma}} \mathrm{Flg}{ }^{\mathrm{ft} / \mathrm{ft}}$ BALB/C congenics is qualitatively different compared to $T m e m 79^{\mathrm{ma} / \mathrm{ma}}$ mice.
\end{abstract}




\section{Introduction}

Atopic dermatitis (AD) is a multifactorial chronic inflammatory skin disorder representing a major socio-economic burden with a steady rise in incidence (reviewed in (Bieber, 2008; Weidinger and Novak, 2016)). AD currently affects up to one third of children in 'Western' countries. Childhood AD strongly predisposes to development of type I allergies and asthma later in life, a phenomenon addressed as the 'atopic march'. All these atopic conditions share a complex genetic predisposition (reviewed in (Otsuka et al., 2017)). Traditionally, defects intrinsic to the immune system resulting in dysregulation of $T$ cell polarization, including dominance of $T_{H} 2$ responses, were thought to be the primary cause of $A D$, type I allergies and asthma. Over the past two decades, however, the discovery of structural defects of the epidermal skin barrier as a cause of systemic immune dysregulation, leading not only to dermatitis, but also increased frequencies of allergic sensitization, high IgE and asthma, shifted this paradigm (Palmer et al., 2006; Walley et al., 2001). Barrier-defective skin allows abnormal penetration of environmental antigen. Presentation of these antigens occurs in the context of an abnormal immune milieu, as stressed skin cells, including keratinocytes, insufficiently protected against environmental hazards, activate innate immune responses. The stressed cells chronically release cytokines that drive the pathogenic Th2 bias and prominent immunoglobulin class switch to IgE that characterizes atopy (Dickel et al., 2010; Kakkar et al., 2012; Roan et al., 2019; Savinko et al., 2012).

Integrity of the epithelial skin barrier depends on continuous proliferative activity of the epidermis maintaining supply of anuclear corneocytes to renew the outermost layer of the skin, the Stratum corneum, which is the most critical component of the skin barrier (reviewed in (Matsui and Amagai, 2015)). The cornified layer is composed of corneocytes tightly connected by specialized desmosomes. The corneocyte is devoid of organelles and essentially consist of a matrix of compacted keratin filaments surrounded by a proteinaceous shell, the cornified envelope, that replaces the plasma membrane. The space between the corneocytes is filled by a complex mixture of lipids, making the cornified layer watertight. While terminally differentiating into corneocytes, keratinocytes express the S100-fused type protein (SFTP) filament aggregating protein (filaggrin, FLG). Full-length profilaggrin, one of the largest human proteins $(400 \mathrm{kDa})$, is proteolytically cleaved into FLG monomers which bind to and bundle keratin intermediate filaments, thereby condensing the cytoskeleton and compacting the cell (Sandilands et al., 2009). FLG is further cleaved into hygroscopic amino acids which represent a 'natural moisturizing factor' (NMF) ensuring appropriate water content but also acidification of the cornified layer (Sandilands et al., 2009).

Genetic defects of FLG were identified as the cause of ichthyosis vulgaris (IV), a common skin disorder characterized by dry and scaly skin (Smith et al., 2006). The mode of inheritance is semi-dominant with heterozygous loss-of-function mutations causing a mild phenotype (Smith et al., 2006). Most patients with severe IV also develop atopy and suffer from AD, allergic sensitizations and asthma (Palmer et al., 2006). Conversely, sequencing of the FLG gene in cohorts of patients with asthma and $A D$ revealed 1 or 2 null alleles in $23 \%$ of cases, establishing genetic FLG deficiency as a major factor predisposing for $A D$ and asthma associated with AD (Palmer et al., 2006; Sandilands et al., 2007)(reviewed in (Irvine et al., 2011)). Strong association of FLG mutations were also reported for pollen and food allergies (reviewed in (Irvine et al., 2011)). 
Given this key role of barrier-defects in atopic disease, animal models of FLG deficiency are of great interest. The flaky tail mouse (Presland et al., 2000) carries genetic defects of two genes involved in epidermal barrier function, the $\mathrm{Flg}^{\mathrm{ft}}$ mutation, a $1 \mathrm{bp}$ deletion ( $\mathrm{Flg}$ 5303delA), resulting in hypomorphic FLG expression (Fallon et al., 2009), and a deleterious mutation in the gene encoding transmembrane protein 79 (Saunders et al., 2013). The Tmem $79^{m a}$ mutation (p.Y280*) results in impaired cornification with matted fur. The two genes are closely linked on mouse chromosome 3 (Saunders et al., 2013). With this dual epidermal barrier impairment, flaky tail mice develop dry and scaly skin, eczema and systemic atopy with increased serum IgE (Fallon et al., 2009; Lane, 1972; Presland et al., 2000).

Addressing the individual contributions of the two genetic defects to the atopic phenotype, Saunders et al. separated the Tmem $79^{m a}$ mutation from the $F / g^{f t}$ allele and showed that isolated loss of Tmem79 results in eczema and increased serum IgE(Saunders et al., 2013). Targeted complete inactivation of $\mathrm{Flg}$ in $\mathrm{C} 57 \mathrm{BL} / 6$ resulted in the IV-like phenotype as expected, however, this mutation did not trigger atopy even after backcrossing to BALB/C (Kawasaki et al., 2012). In striking contrast to this finding, Saunders et al. reported that extensive backcrossing of the $F / g^{f t}$ mutation to BALB/C yielded mice which developed severe skin inflammation with important features of $A D$, including elevated serum IgE levels, eosinophilia and accumulation of IL-5-producing ILC2s. (Saunders et al., 2016). Most importantly, these $\mathrm{Flg}^{f t}$ BALB/C congenics uniformly show high levels of total IgE and develop spontaneous asthma, thus reproducing the 'atopic march' observed in many human patients (Saunders et al., 2016). These findings established $\mathrm{Flg}^{\mathrm{ft} / \mathrm{ft}} \mathrm{BALB} / \mathrm{C}$ congenic mice as a highly relevant model for human atopy associated with skin barrier defects.

The human FLG and mouse Flg genes are encoded within a large cluster of genes functioning in formation and maintenance of the skin barrier, the epidermal differentiation cluster (EDC) and are in strong linkage disequilibrium with the entire EDC. To determine whether genetic variability within the EDC and adjacent regions may account for the phenotypic difference between the $\mathrm{Flg}^{\mathrm{ft} / \mathrm{ft}}$ BALB/C congenics (Saunders et al., 2016) and the Flg knock out mice (Kawasaki et al., 2012), we generated Flg-deficient mice on a pure BALB/c background and analysed them for skin phenotype and systemic atopy. We also performed whole genome sequencing for comparison of the $\mathrm{Flg}{ }^{\mathrm{ft} / \mathrm{ft}} \mathrm{BALB} / \mathrm{C}$ congenics and our new BALB/C Flg ${ }^{-/}$line.

\section{Results}

\section{Generation of BALB/c $\mathrm{Flg}^{-/-}$mice}

For inactivation of the Flg gene, two guide RNA sequences were chosen. Guide 1 targeted the upstream, non-repetitive portion of exon 3, whereas guide 2 bound each of the repeat regions of exon 3 (Fig. 1A). The guides were microinjected into BALB/C zygotes and mutant offspring were identified by PCR (Fig S1). We found three mutant Flg alleles that harbored large deletions of the upstream non-repetitive region plus at least $1 \mathrm{Flg}$ repeat as determined by PCR (Fig S1 B and C). The mutations were bred to homozygosity and total tail and ear skin samples from 8 week-old mice were analyzed by Western blot, demonstrating complete absence of both, full-length profilaggrin and monomeric filaggrin protein (Fig 1B). This result was confirmed by immunofluorescence analysis with no filaggrin protein expressed in skin of $\mathrm{Flg}^{-/}$mice (Fig 1C). Mice homozygous for allele 1 (Fig. S1C) were used in subsequent experiments. Long read single molecule real-time (SMRT) sequencing (PacBio) revealed that this line carried a large (8122 bp) out-of-frame deletion ( Fig. 1A). In sum, we successfully generated FLG-deficient mice on a pure BALB/C background. 


\section{BALB/c Flg mice develop an ichthyosis vulgaris-like phenotype}

While normal immediately after birth, homozygous Flg-deficient pups became conspicuous few days later for their dry and scaly skin, hyperlinearity and annular constrictions of the tail skin (Fig. 2A and B). This phenotype ameliorated over the first few weeks post-partum and the skin appeared macroscopically normal at latest by the age of 4 weeks (not shown). There was no evidence of pruritus and the fur of adult mice was indistinguishable from that of control littermates. Hematoxylin and eosin staining of skin sections revealed marked reduction of keratohyalin granules in the upper $\mathrm{Flg}^{-/-}$epidermis (Stratum granulosum), consistent with lack of Flg as the major constituent of these granules and reproducing a histological hallmark of IV (Sybert et al., 1985). Apart from loss of keratohyalin granules, $\mathrm{Flg}^{-}$

- epidermis appeared normal, as did the dermis with no evidence of inflammatory infiltration. While $\mathrm{Flg}^{-1}$ ears were invariably smaller (not shown) and thicker (Fig. 2C) as had been described for the flaky tail strain (Lane, 1972), no overt histological changes were observed in ear skin. Transepidermal water loss (TEWL) was unchanged compared to controls in younger $\mathrm{Flg}^{-1-}$ mice (8-10 weeks), but was clearly increased in older filaggrin deficient (16-18 weeks) animals compared to age-matched controls (Fig. 2D).

Collectively, we find that loss of FLG on a pure BALB/c background results in dry and scaly skin in neonates. In adult mice, skin and fur are macroscopically normal. Increased TEWL occurs in older BALB/C Flg ${ }^{-/-}$animals, but not in younger adults, indicative of a defect in the skin barrier in adult $\mathrm{Flg}^{-/-}$mice.

\section{BALB/C Flg ${ }^{-/}$skin features mild immune activation and altered microbiome}

Skin barrier defects can result in systemic immune dysregulation through cytokine release of stressed epidermal cells that are insufficiently protected against environmental hazards. In order to test, whether the loss of physiological Flg expression in the suprabasal epidermis leads to detectable stress responses of cells of lower epidermal strata, we performed RNA sequencing of FACS-sorted CD45-negative ITGA6 (CD49f) ${ }^{+}$basal keratinocytes of young adult control and BALB/C Flg ${ }^{-1-}$ mice (Fig. S3A). Irrespective of genotype, transcripts known to be expressed by basal layer keratinocytes were abundant (keratin 1, 5 and 10) while genes expressed only in suprabasal cells, including Flg, IVI (involucrin), lor (loricrin), Tgm (transglutaminase) 1, 3 and 5 were not detected, validating the experiment. In accordance with the moderate changes observed macroscopically and histologically, only few genes showed a significant up-regulation and we observed this only in female mice, while males did not feature significantly altered gene expression. Among the genes upregulated in females were several genes encoding components of the $\mathrm{MHC}$ class II antigen presentation machinery, including $H 2-A a, H 2-A b 1, H 2-E a, C D 74$ (encoding invariant chain) and $H 2-D M b 1$ (Fig. 3A). qRT PCR analysis for $C d 74$ and $\mathrm{H} 2-A a$ were found upregulated (although not statistically significant for individual genes) (Fig. 3B). Flow cytometric analysis of skin cell suspensions demonstrated a doubling of $\mathrm{MHC}$ class II expressing keratinocytes in female mice (Fig. 3C). Patches of brightly MHC II-positive keratinocytes were recently identified as critical structures in antimicrobial T cell responses in the skin (Tamoutounour et al., 2019). We also found a robust upregulation of the Retnla gene encoding restin-like molecule alpha (RELM $\alpha$ ) in sorted female, but not male $\mathrm{Flg}^{-\%}$ basal keratinocytes (Figure $3 \mathrm{~A}$ and B). RELM $\alpha$ is a marker of $\mathrm{M} 2$ macrophage differentiation and was also demonstrated to function as an important keratinocyte antibacterial effector protein (Harris et al., 2019). While expression 
of IL-33 was not different between BALB/C Flg ${ }^{-/-}$mice and controls (not shown), IL-1 $\beta$ mRNA levels, while unchanged in young adults, were clearly increased in 20 weeks-old mice (Figure 3D).

To determine whether absence of Flg affects the skin microbiome, we swabbed cheek skin of 8 week-old female BALB/C Flg ${ }^{-\%}$ and control mice co-housed in the same cages and performed 16s ribosomal RNA sequencing. As expected for mouse skin, Bacteroides, Proteobacteria and Firmicutes were the dominant phyla without major changes of their abundance in mutants versus controls (Fig. S3B). BALB/C Flg ${ }^{-1-}$ mice showed a reduction of microbial diversity compared to control as indicated by Shannon diversity index (Fig. 3E). Several taxa of the families Muribaculaceae,previously known as S24-7 (Lagkouvardos et al., 2019) or Lachnospiraceae were dramatically reduced in $\mathrm{Flg}^{-/}$versus control mice. In addition, we observed significant reductions of few specific species of the Ruminococcaceae, Lactobacillaceae and Rikenellaceae families. Compared to these results, the alterations of skin microbiome observed in $F / g^{f t / f t}$ BALB/C congenics were clearly more profound with a striking over-representation of Firmicutes.

Collectively, we find that loss of Flg in mice results in mild immune activation in the skin that increases with age and reduced diversity of skin microbiota.

\section{$\mathrm{BALB} / \mathrm{C} \mathrm{Flg} /$ skin shows slight increase in T cell compartment but otherwise unchanged immune cell populations}

To assess effects of the loss of filaggrin on the local immune system, we quantified immune cells in BALB/C Flg ${ }^{-/-}$skin by flow cytometric analysis of skin cell suspensions. Importantly, $\mathrm{CD} 45^{+}$hematopoietic cells were not increased in relation to non-hematopoietic skin cells (mostly keratinocytes), confirming the absence of inflammatory infiltration observed histologically (Fig. 4A). While $\mathrm{Flg}^{\mathrm{ft} / \mathrm{ft}} \mathrm{BALB} / \mathrm{C}$ congenics feature larger eosinophil, mast cell and ILC2 populations (Saunders et al., 2016), we did not observe any increase in eosinophils, mast cells, neutrophils or ILC2s in BALB/C Flg ${ }^{-/-}$mice versus controls (Fig. $4 \mathrm{~B}$ and E). We also found $\mathrm{CD} 86$ expression by $\mathrm{CD} 11 \mathrm{C}^{+}$cells and the size of the intraepidermal Langerhans cell population unchanged in BALB/C Flg ${ }^{-/-}$compared to control animals (Fig. $4 \mathrm{C}$ and D). We consistently observed a moderate increase in $\mathrm{T}$ cells that was most likely accounted for by expansion of the $\gamma \delta$ T cell population (Fig. 4F).

In summary, Flg-deficient mice on pure BALB/C background do not feature increased numbers of total immune cells in the skin. While we detected some increase in skin $\mathrm{T}$ cell numbers, these mice do not display the key inflammatory changes reported for young $\mathrm{Flg} \mathrm{g}^{\mathrm{ft} / \mathrm{ft}}$ $\mathrm{BALB} / \mathrm{C}$ congenics, in particular the accumulations of ILC2s, eosinophils and neutrophils (Saunders et al., 2016).

\section{No sign of atopy in BALB/C $\mathrm{Flg}^{-/-}$mice}

$\mathrm{BALB} / \mathrm{C} \mathrm{Flg} \mathrm{g}^{-1-}$ mice developed the ichthyotic phenotype with scaly tail and hyperlinearity, but did not show overt skin inflammation at any time point (Fig $2 \mathrm{~A}$ and S2). To test the Flg mutants for systemic atopy, total serum IgE concentrations were quantified by ELISA. In contrast to $\mathrm{Flg}{ }^{\mathrm{ft} / \mathrm{ft}}$ BALB/C congenics (Saunders et al., 2016), IgE levels of our BALB/C Flg ${ }^{-/-}$ mice at 8,12 and 25 weeks of age did not differ significantly from levels in BALB/c controls (Fig. 5A). As the skin microbiome is an important environmental trigger factor for $A D$ with important roles for S. aureus (reviewed in (Geoghegan et al., 2018)), we tested whether colonization of Flg-deficient mice with S.aureus isolates from AD patients would result in skin inflammation and systemic atopy. $\mathrm{Flg}^{-/-}$animals were painted on the shaved trunk ( 5 times at two day intervals) with a suspension of a S.aureus CC1 isolated from an AD patient. The mice 
were monitored for 7 weeks thereafter, however, no overt skin inflammation (not shown) or increase in total serum IgE (Fig. 5B) was observed. As skin colonization can be impeded by the resident flora, we repeated the S.aureus colonization with prior systemic antibiotic treatment, but also this regime did not trigger skin inflammation or enhanced IgE production in our BALB/C Flg ${ }^{-1-}$ mice (Fig. $5 \mathrm{~B}$ ). To test whether the altered cutaneous immune milieu of $\mathrm{Flg}^{-/-}$mice (Fig. 3A-D) would drive abnormal IgE responses upon exposure to exogenous antigen through the skin, we epicutaneously immunized BALB/C $\mathrm{Flg}^{-/-}$mice with OVA. OVAspecific IgE was not significantly different between mutant and BALB/C control littermates 7 weeks later (Fig. $5 \mathrm{C}$ ). We next repeated the epicutaneous OVA immunization in $\mathrm{Flg}^{-/-}$or control BALB/C that had been transferred OVA-specific DO11.10 transgenic (Murphy et al., 1990) IL-4eGFP (4get) T reporter cells (Mohrs et al., 2001). As our finding that TEWL increased in older (16-18 weeks old), but not in younger mice (8-10 weeks old), indicated that the barrier defect develops with age, we included mice of both age groups. Application of OVA to the skin of DO11.10 T cell recipients did not cause any skin alteration in wild-type, or younger $\mathrm{Flg}^{-/}$recipients (not shown), whereas marked skin inflammation was elicited in 16-week-old Flg-deficient recipient mice (Fig. 5D). To further investigate the differences in the development of skin inflammation in D011.10 cell recipient Flg-deficient but not wildtype recipient mice, we assessed D011.10 cellular responses in the skin draining LNs (Fig 5.E). In the LNs of Flg-deficient mice, but not control recipient wild-type mice, there was vigorous cell proliferation with elevated frequencies of IL-4-eGFP ${ }^{+}$cells) indicating enhanced OVA-specific Th2 cellular response in skin $\mathrm{LN}$ of $\mathrm{Flg}^{-/-}$(Fig. 5E).

In summary, we show that loss of Flg in mice of pure BALB/C background does not result in increased total serum IgE, neither spontaneously nor after colonization with S.aureus. Also epicutaneous immunization did not elicit more specific $\mathrm{IgE}$ in BALB/c $\mathrm{Flg}{ }^{-/}$mice compared to control mice, but did induce enhanced $T$ cell proliferation and skin inflammation in recipients of antigen-specific transgenic T cells.

\section{Accurate whole genome sequencing reveals that $F g^{f t / f t}$ BALB/C congenic mice are in fact Flg ${ }^{f t / f t}$ Tmem $79^{m a / m a}$ double mutants, explaining their atopic phenotype}

Our finding that complete loss of Flg in mice of pure BALB/C background did not result in detectable atopy, contrasting with the robust atopic phenotype of $F / g^{f t / f t}$ BALB/C congenics (Saunders et al., 2016), suggested that further genetic variation within the congenic interval in addition to the Flg loss-of-function mutation is essential for development of atopy in FLGdeficient animals.

We therefore generated a highly accurate whole genome sequence of the $F / g^{f t / f t} \mathrm{BALB} / \mathrm{C}$ congenic strain and our newly generated BALB/C Flg ${ }^{-/}$mice using PacBio long read singlemolecule real-time sequencing (Eid et al., 2009; Wenger et al., 2019)). Average high-fidelity ( $\mathrm{HiFi}$ long read coverage was $16.7 \mathrm{x}$ for the $\mathrm{Flg}{ }^{\mathrm{ft} / \mathrm{ft}} \mathrm{BALB} / \mathrm{C}$ congenic strain and $14.7 \mathrm{x}$ for the $\mathrm{BALB} / \mathrm{C} \mathrm{Flg}{ }^{-/}$strain. Both strains were assembled using the de novo assembler hifiasm (version 0.7). We used the BALB/C Flg ${ }^{-/}$assembly to map the read sets of both genomes for comparison of variations. To identify chromosome 3 contigs, the BALB/C Flg ${ }^{-1-}$ assembly was mapped to the GRCm38.p6 reference with minimap2 (version 2.17-r941). Annotation was performed by lift-over from the $M$. musculus $\mathrm{GRCm} 38$ genome built 6 . Chromosome 3 alignments were used for variant analysis followed by variant effect prediction. Both de novo assemblies of chromosome 3 and annotations can be downloaded from https://bds.mpicbg.de/hillerlab/Bat1KPilotProject/.

In the $F / g^{f t / f t}$ BALB/C congenic sequence, we identified the Flg 5303delA frame shift mutation in repeat 6 , as expected, and the sequence of the new BALB/C Flg ${ }^{-/}$line revealed the size of 
the deletion we had introduced by CRISPR/Cas9-mediated mutagenesis (Fig. 1). Alignment of the new chromosome 3 sequence of $\mathrm{Flg}^{\mathrm{ft} / \mathrm{ft}} \mathrm{BALB} / \mathrm{C}$ congenic and BALB/C $\mathrm{Flg}^{-1}$ mice demonstrated that chromosome 3 (and all other chromosomes, not shown) of the two strains were nearly identical with our BALB/C Flg ${ }^{-1}$ de novo assembly, with an average of 1 variation per 9694 bp outside of the congenic interval (QV score 39.9). However, the two sequences extensively differed within a $51.3 \mathrm{MB}$ congenic interval, with an average of 1 variation per $145 \mathrm{bp}$ (QV score 21.6) (Fig. 6). This interval was in roughly equal parts derived from $\mathrm{C} 3 \mathrm{H}(27 \mathrm{MB}$, near perfect match with $\mathrm{C} 3 \mathrm{H}$ in all positions for which published $\mathrm{C} 3 \mathrm{H}$ sequence information was available) and from C57BL/6 (24.3 MB) in the $\mathrm{Flg}^{\mathrm{ft} / \mathrm{ft}} \mathrm{BALB} / \mathrm{C}$ congenic strain. These findings reflect the history of sequential backcrossing of the $\mathrm{Flg}^{\mathrm{ft} / \mathrm{ft}}$ mutation first to C57BL/6 (Saunders et al., 2013) and then to BALB/C (Saunders et al., 2016). Within the $51.3 \mathrm{MB}$ congenic interval we identified 610 genes having functional annotations. Of these, 12 differed between the $\mathrm{Flg}^{\mathrm{ft} / \mathrm{ft}} \mathrm{BALB} / \mathrm{C}$ congenic and the BALB/C Flg ${ }^{-/}$strain by deleterious mutations (frame shift, gain or loss of stop codon, loss of start codon or loss of splice site), while 143 genes differed by amino acid exchange mutations predicted to potentially impact on structure or function (Table S1).

Among the deleterious mutations, we unexpectedly found, the Y280Stop mutation of the Tmem79/mattrin gene (Saunders et al., 2013), located in the $\mathrm{CH}$-derived interval of the $\mathrm{Flg}^{f t / f t}$ BALB/C congenic mice. The $\mathrm{Flg}^{f t}$ mutation originally arose on a strain (mixed background, partially $\mathrm{C} 3 \mathrm{H}$ ) with matted hair phenotype to yield the flaky tail mouse (Fallon et al., 2009; Lane, 1972; Presland et al., 2000). Saunders et al. identified the Y280Stop mutation of Tmem79, a gene in linkage disequilibrium with Flg on chromosome 3, to be responsible for the matted phenotype and re-named the gene mattrin (Saunders et al., 2013). In order to separate the $F / g^{f t}$ and the Tmem $79^{m a}$ mutations, Saunders et al. bred flaky tail mice to $\mathrm{C} 57 \mathrm{BL} / 6$ and reported that homozygous $\mathrm{Tmem} 79^{\mathrm{ma} / \mathrm{ma}}$ mice (wild type for $\mathrm{Flg}$ ) showed severe systemic atopy with eczema, spontaneous increase in IgE levels and asthma (Saunders et al., 2020; Saunders et al., 2013), and also identified a human TMEM79 missense SNP associated with human AD (Saunders et al., 2013). Flg ${ }^{\text {ft/ft }} \mathrm{C57BL} / 6$ mice (assumed to be wild type for Tmem 79) were backcrossed extensively to BALB/C to yield the $F / g^{f t / f t}$ BALB/C congenic strain that is characterized by a prominent atopic phenotype, including eczema, high IgE and spontaneous asthma (Saunders et al., 2016; Schwartz et al., 2019). Our sequencing result, however, demonstrates that the $\mathrm{Flg}^{\mathrm{ft} / \mathrm{ft}}$ BALB/C congenic strain is homozygous for the Tmem $79^{m a}$ mutation, indicating that either the two mutations had not been successfully separated, or that the $T m e m 79^{m a} F / g^{f t}$ haplotype was accidentally reintroduced during backcrossing to BALB/C.

The phenotype of mice with isolated lack of Tmem79 is strikingly similar to that of the $F / g^{f t / f t}$ BALB/C congenics. Young adult Tmem $79^{m a / m a}$ mice (Saunders et al., 2020) develop eczema with the same kinetics, macroscopic appearance and severity as reported for the $\mathrm{Flg} g^{\mathrm{ft} / \mathrm{ft}}$ BALB/C congenics. Neonatal ichthyosis does not occur in Tmem $79^{m a / m a}$ mice due to intact Flg. Tmem $79^{m a / m a}$ mice also reproduce the high serum $\operatorname{lgE}$ and spontaneous lung inflammation of $F / g^{f t / f t}$ BALB/C congenics (Saunders et al., 2020). Genotyping of $F / g^{f t / f t}$ BALB/C congenic mice for the $T m e m 79^{m a}$ and $F l g^{f t}$ mutations confirmed the sequencing data, with both Tmem79 and Flg mutations detected. It is therefore, indicative that the atopic phenotype of $F / g^{f t / f t}$ BALB/C congenics is caused by the Tmem $79^{m a}$ mutation. However, also differences in other genes located in the congenic interval could contribute to and modulate skin inflammation and atopy in $F / g^{f t / f t} B A L B / C$ congenic mice. The list of genes for which the $\mathrm{Flg}{ }^{f t / f t}$ BALB/C congenics and our BALB/C $\mathrm{Flg}^{-/-}$animals show relevant (deleterious or structurally/functionally damaging) differences contains several genes with functions in skin 
barrier, including crnn (encoding cornulin), Flg2, and $I V I$ (endoding involucrin), and genes with functions in the immune system, such as Fcgr1, Pglyrp3 and Arnt (Table S1) Collectively, we show that the decisive difference between non-atopic BALB/C Flg- mice and the atopic $\mathrm{Flg}^{\mathrm{ft} / \mathrm{ft}} \mathrm{BALB} / \mathrm{C}$ congenic strain is the unexpected presence of the atopy-causing Tmem $79^{m a}$ mutation in the latter.

\section{Discussion}

To resolve the unexplained discrepancy between prominently atopic Flg-deficient $\mathrm{Flg} \mathrm{g}^{\mathrm{ft}}$ BALB/C congenic mice (Saunders et al., 2016) and mice with targeted inactivation of Flg (Kawasaki et al., 2012), and to determine the effects of Flg deficiency on skin immune regulation, we generated Flg-deficient mice on a pure BALB/C background by inactivating the Flg gene in BALB/c embryos. These animals do not develop systemic atopy. We sequenced the genome of the atopic Flg ${ }^{f t}$ BALB/C congenics (Saunders et al., 2016) and discovered that these animals unexpectedly harbor the atopy-causing matted mutation of the Tmem 79 gene $\left(\right.$ Tmem $79^{m a}$ ) that is linked to the Flg locus. The genome sequencing data was validated by genotyping, with both $\mathrm{Tmem} 7 \mathrm{~g}^{\mathrm{ma}}$ and $\mathrm{Flg} \mathrm{g}^{f t}$ mutations present in the $\mathrm{Flg}{ }^{\mathrm{ftft}}$ BALB/C congenic mice. These findings shed light on the hitherto puzzling and conflicting published results on skin barrier-defective mouse models.

In accordance with the phenotype of Flg knock out mice (Kawasaki et al., 2012), our BALB/C $\mathrm{Flg}^{-/}$mice demonstrate that, in mice, loss of Flg results in dry and scaly skin only postnatally, while skin and fur are macroscopically normal throughout adult life. Histologically, substantial reduction of keratohyalin granules is the only prominent change. Loss of Flg alone does not result in spontaneous development of overt inflammation as our BALB/C $\mathrm{Flg}^{-1}$ mice, like the published Flg knock out line (Kawasaki et al., 2012), show no macroscopic dermatitis. Also histologically, we could not detect any inflammatory skin changes in line with Kawasaki et al., who reported no inflammatory infiltration (Kawasaki et al., 2012). Flgdeficiency, however, is clearly not immunologically inert. As was reported in the published Flg knock out line (Kawasaki et al., 2012), we observed enhanced adaptive responses to epicutaneously administered antigen, most likely reflecting abnormal antigen penetration. We also found spontaneous changes in the skin immune system. Slight alterations in BALB/C $\mathrm{Flg}^{-1 /}$ keratinocyte gene expression suggest local immune activation. Moreover, while total numbers of immune $\left(\mathrm{CD} 45^{+}\right)$cells in the skin were not increased in skin of Flg-deficient mice, we observed, changes in numbers of skin-resident immune cells by flow cytometry, i.e. a moderate expansion of T cells. However, the marked increases in ILC2s, eosinophils and mast cells that characterizes the Tmem $79^{m a / m a} F / g^{f t / f t}$ BALB/C congenics (Saunders et al., 2016; Schwartz et al., 2019) do not occur in our BALB/C Flg ${ }^{-1-}$ mice. Absence of Flg results in no detectable change of TEWL in young adults, however, we found water loss increased in older mice. To test whether increased TEWL in older animals correlated with increased $\mathrm{Ag}$ penetration, we epicutaneously immunized 8 week-old (not shown) and 16 week-old Flgdeficient and control mice. No sign of skin inflammation was observed in control mice or in 8-week-old flg-deficient mice. However, in 16-week-old $\mathrm{Flg}^{-1-}$ mice we observed eczematous skin inflammation, increased OVA-specific T cell proliferation and increased IL-4 production in the skin draining lymph nodes. In addition, we found a sponantous induction of $I L-1 b$ transcription in total skin, suggesting that age related loss of epidermal barrier resulted in immune activation. The microbiome of BALB/C Flg $\mathrm{g}^{-/}$skin clearly differs from microbiomes of 
control skin with reduced diversity and systematic reduction of particular species. However, these changes are less pronounced and qualitatively different compared to the gross skin microbiome alteration in Tmem $79^{\mathrm{ma} / \mathrm{ma}} \mathrm{Flg}{ }^{\mathrm{ft} / \mathrm{ft}}$ BALB/C congenics (Saunders et al., 2016; Schwartz et al., 2019) which display a striking overrepresentation of firmicutes (Schwartz et al., 2019). The effects of filaggrin deficiency on skin microbiota may either be a direct consequence of the lack of Flg and resulting changes of skin $\mathrm{pH}$, moisture and turnover or texture of the cornified layer, or could be a result of the subtle immune-activation we observed in the BALB/C Flg ${ }^{-\%}$ animals. Obviously, additional loss of Tmem79 will also significantly impact the skin microbiome.

Importantly, we now show that the atopic phenotype of $F l g^{f t / f t}$ BALB/C congenics (Saunders et al., 2016) with dermatitis, increased serum IgE and spontaneous asthma, is likely caused by the $T$ mem $79^{m a / m a}$ mutation that is linked to the $F g^{\text {ft }}$ allele and was not known to be present in this strain. Mice with isolated Tmem79 deficiency develop a largely similar phenotype (Saunders et al., 2020; Saunders et al., 2013), which is in sharp and previously unexplained contrast to the complete lack of atopy in the published Flg knock out line (Kawasaki et al., 2012) and our BALB/C Flg ${ }^{-/}$animals. Both lines feature neither dermatitis, increase in serum IgE, nor lung inflammation. Not even after colonization with S.aureus isolates from $A D$ patients did IgE levels rise in BALB/C $\mathrm{Flg}^{\%}$ animals.

Future experiments are required to elucidate whether lack of $F l g$, while not causing atopy alone, nevertheless modulates skin inflammation and systemic atopy of Tmem79-deficient mice. Comparison of findings in Tmem $79^{\mathrm{ma} / \mathrm{ma}} \mathrm{Flg} \mathrm{g}^{\mathrm{ft} / \mathrm{ft}} \mathrm{BALB} / \mathrm{C}$ congenic mice (Saunders et al., 2016; Schwartz et al., 2019) and in Tmem 79 ${ }^{m a / m a}$ C57BL/6J congenic animals (Saunders et al., 2020; Saunders et al., 2013) are confounded by the difference in strain background. The difference in skin phenotype between the mice could be caused by the absence of Flg. Alternatively, however, additional genetic variation in the respective congenic interval could exert modulating effects on skin inflammation and atopy of $T m e m 79^{m a / m a} F / g^{f t / f t}$ mice. It is noteworthy that the genes significantly altered in $T m e m 79^{m a / m a} \mathrm{Flg} g^{f t / f t}$ mice include several barrier genes (Table S1), but also genes with known functions in the immune system.

Defects of the epidermal skin barrier one of the most important predisposing factor for atopic disease, notably not only for atopic dermatitis, but also for systemic atopy, i.e. allergic sensitizations and asthma (Palmer et al., 2006). FLG deficiency, the cause of ichthyosis vulgaris, is arguably the most important barrier defect associated with atopy. Our finding that lack of Flg is not sufficient to cause eczema and systemic atopy in mice is line with the fact that a large fraction of IV patients homozygous for FLG null alleles never develop atopic dermatitis, allergic sensitizations or asthma. Our result highlights the essential role of atopy promoting variants of other genes required to synergize with FLG deficiency in causing the atopic predisposition. Also in human atopy, defects of other 'barrier genes' linked to FLG in the EDC and adjacent regions may contribute to the atopic phenotype. Mouse models with defects of one or several 'skin barrier genes', including the $T m e m 79^{m a / m a} F l g^{f t / f t}$ BALB/C congenics, will be instrumental in understanding systemic immune dysregulation in atopy associated with compromised skin barrier.

\section{Acknowledgement}


This work was funded by DFG grants RO2133/9-1 to A.R. and DA 1311/3-1 to A.D. in the setting of FOR2599 and was supported by Federal Ministry of Education and Research (BMBF grant 01IS18026C). We thank Werner Müller for helpful discussion. Christina Hiller, Livia Schulze, Madelaine Rickauer and Tobias Häring provided expert technical assistance.

\section{Legends}

\section{Figure 1}

Generation of Flg-/- mice on a pure BALB/C background.

A) Strategy for CRISPR/Cas9-mediated targeting of the Flg gene. While guide 1 binds a single site in the upstream, non-repetitive region of exon 3, guide 2 binds to each of the near perfect $\mathrm{Flg}$ repeats. Among others we obtained mutant 'allele1' that was bred to homozygosity to obtain $\mathrm{Flg}^{-/}$mice used in subsequent experiments. Long read single molecule real-time sequencing revealed that allele1 contained a $8122 \mathrm{bp}$ (out-of-frame) deletion.

B) Expression of FLG in ear skin as determined by western blot analysis of ear skin from 8 week-old mice. Expected size for full-length profilaggrin is approximately $500 \mathrm{kDa}$ and approximately $30 \mathrm{kDa}$ for the FLG monomer. Representative of 8 animals.

C) Immunofluorescence analysis FLG expression (green) in tail skin of 8-week-old control $\left(\mathrm{Flg}^{\mathrm{wt} /-}\right)$ and $\mathrm{Flg}^{-/-}$mice. Nuclei counterstained with DAPI (red). Representative images from 4 mice of each genotype. Dotted lines mark basement membrane and the border of epidermis to cornified layer. Scale bar $100 \mu \mathrm{M}$.

\section{Figure S1}

Generation and genotyping of BALB/C $F / g^{-/}$mice

A) Numbers of BALB/C zygotes injected with Cas9-RNPs, transferred embryos, number of viable offspring resulting from these transfers and numbers of founders harboring large deletions involving cleavage by both guides.

B) Strategy for PCR-based identification of mutant Flg alleles. Separate reactions were performed with primer pairs FOR-REV1 and FOR-REV2.

C) PCR result for mutant allele 1 , resulting from deletion downstream of the guide 1 target site and one of the guide 2 target sites with loss of $F l g$ repeats. The deletion results in absence of the FOR-REV1 product and alters the length of product FOR-REV2.

\section{Figure 2}

Skin phenotype of BALB/C $\mathrm{Flg}^{-/}$mice.

A) Representative macroscopic and microscopic images of neonatal (d4) BALB/c control and $\mathrm{Flg}^{-1}$ ear skin. Lower panels: H\&E staining of epidermis. Insets from larger images shown in Fig. S2. Arrowheads denote keratohyalin granules of control skin. Images representative of at least 10 mice. Scale bar $100 \mu \mathrm{M}$.

B) Representative macroscopic images of 3 week-old BALB/C control and $\mathrm{Flg}^{-/}$tails.

C) Ear thickness of 8 week-old BALB/C littermate control $(n=14)$ and $\mathrm{Flg}^{-/}(n=13)$, male and female both groups. Means $\pm S D, * * * * p<0.0001$.

D) Transepidermal water loss (TEWL) of shaved BALB/C control and Flg ${ }^{-/}$back skin. Means \pm SD, $* * * p<0.001, \mathrm{~ns}$, not significant. 


\section{Figure S2}

Ear skin histology of BALB/C Flg ${ }^{-/}$and control mice. H\&E staining. Insets indicate the images shown in Fig. 2A. Images representative of at least 10 mice. Scale bar $100 \mu \mathrm{M}$.

\section{Figure 3}

Alteration of keratinocyte gene expression and composition of microbiota of $\mathrm{Flg}^{-/}$skin.

A) RNA sequencing analysis of basal CD49f ${ }^{+}$keratinocytes (negative for CD45, see also Fig S3), sorted from skin cell suspensions of four 8-12 week-old female $\mathrm{Flg}^{-1-}$ mice and 5 littermate controls. Heat map represents expression of genes involved in antigen presentation and the Retnla gene (relative expression, individual read counts corrected for the mean expression of the respective gene), $p<0.05$ for all genes.

B) Validation of results in A) by qRT-PCR for selected genes on RNA extracted from basal keratinocytes sorted as in A). Fold change for individual female $\mathrm{Flg}^{-/}$mice displayed as fold change compared to mean of 6 controls (set to 1). Means $\pm S D,{ }^{*} p<0.05$, ns, not significant.

C) Frequency of CD45-negative epidermal cells expressing $\mathrm{MHCll}$ as determined by flow cytometric analysis of skin cell suspensions from 8-10 week-old $\mathrm{Flg}^{-/}$and control females. $\mathrm{n}=8$ both groups. Means $\pm S D, p<0.05$.

D) Relative fold change of IL-1 $\beta$ mRNA in total ear skin RNA from young adult ( 8 wk-old)) and older (20 wk-old) $\mathrm{Flg}^{-/}$BALB/C mice compared to controls. Means $\pm \mathrm{SD}, \mathrm{n}=8$ both groups, ${ }^{* *} p<0.01$, ns, not significant.

E) Composition of the skin microbiome of 8 week-old female BALB/C Flg ${ }^{-/}$and control cohoused females. Left: comparison of Shannon diversity index. Right: Phylogeny and abundance of taxa that were significantly depleted in $\mathrm{Flg}^{-1}$ mice. Branch label colors are indicative of the bacterial order that the respective amplicon sequence variant (ASV) was assigned to. Heatmap displays log2 fold change of each ASV for the comparison of $\mathrm{Flg}^{-1}$ versus control.

\section{Figure S3}

A) Gating strategy and post-sort reanalysis of the flow cytometric purification of basal (CD49f ${ }^{+}$) keratinocytes.

B) Relative abundance of microbial phyla in cheek skin swabs from 8 week-old female $\mathrm{BALB} / \mathrm{C} \mathrm{Flg}{ }^{-/}$and control co-housed females

\section{Figure 4}

Flow cytometric analysis of immune cells in skin cell suspensions from 8-12 wk-old BALB/C $\mathrm{Flg}^{-/}$and control female mice. $\mathrm{N}=5-6$ both groups.

A) Fraction of $\mathrm{CD}_{4} 5^{+}$cells in viable ear skin cells. (Cell suspension was generated by digestion of total minced ears. Absolute numbers of CD45-negative cells, mostly keratinocytes were not significantly different between mutant and control skin, not shown). Means \pm SD.

B) Fractions of $\mathrm{CD}_{11} \mathrm{~b}^{+}$SiglecF ${ }^{+}$eosinophils, $\mathrm{CD} 11 \mathrm{~b}^{+} \mathrm{Gr}-\mathrm{1}^{\mathrm{hi}}$ neutrophils and $\mathrm{CKit}^{+} \mathrm{FceRI} \mathrm{I}^{+}$mast cells (MCs) among CD45 ${ }^{+}$cells. Means \pm SD.

C) Mean CD86 expression on $\mathrm{CD} 45^{+} \mathrm{CD} 11 \mathrm{c}^{+}$cells. Means $\pm \mathrm{SD}$.

D) Fraction of $\mathrm{EpCAM}^{+} \mathrm{CD} 45^{+}$Langerhans cells among total viable epidermal cells. Cell suspension was generated by digestion of epidermal sheets. Means \pm SD.

E) Fraction of $\mathrm{CD}^{-} \mathrm{Thy}^{+}{ }^{+} \mathrm{IL} 7 \mathrm{Ra}^{+} \mathrm{ICOS}{ }^{+} \mathrm{CD} 25^{+} \mathrm{ILC} 2 \mathrm{~S}$ among $\mathrm{CD} 45^{+}$cells. Means $\pm \mathrm{SD}$.

F) Fractions of total $C D 3^{+} T$ cells and $\gamma \delta$ T cells among $C D 45^{+}$cells. Means $\pm S D,{ }^{*} p<0.05$. 


\section{Figure S4}

Gating strategies for quantification of individual immune cell populations in total skin cell suspensions or epidermal cell suspensions (in the case of Langerhans cells). A) Whole ear skin $\mathrm{CD}_{4} 5^{+}$cells, B) $\gamma \delta T C R^{+} \mathrm{T}$ cells, C) ILC2 population, D) epidermal Langerhans cells, E) eosinophils, F) neutrophils, $G$ ) mast cells.

\section{Figure 5}

LosS of Flg in mice of pure BALB/c background does not result in atopy

A) Quantification of total serum IgE of BALB/C Flg $(n=5-8)$ and littermate control mice $(n=5)$ by ELISA at indicated age. Means \pm SD.

B) Serum IgE levels (as in A) of 14-16 week-old BALB/C Flg ${ }^{-/}(n=5-8)$ and littermate control mice ( $n=5$ or 6 ) colonized with a S.aureus isolate from an AD patient (CC1 strain) without or with prior systemic antibiotic treatment (ABX). S.aureus wt group $n=6$, ko group $n=8$. $A B X$ / $S$. aureus groups $n=5$ both genotypes. Means $\pm S D$.

C) Quantification of OVA-specific serum IgE levels (ELISA) of 16 week-old BALB/C Flg ${ }^{-/}(n=14)$ and littermate control mice $(n=7)$ immunized epicutaneously with OVA. Means \pm SD.

$\mathrm{D}$ and $\mathrm{E}$ ) Immune response of $\mathrm{BALB} / \mathrm{C} \mathrm{Flg}{ }^{-/}$recipients of OVA-specific transgenic D011.10 T cells to epicutaneous OVA immunization. 16 -week-old mice received i.v. transfer of $2 \times 10^{6}$ MACS-purified, splenic CD4 ${ }^{+} \mathrm{T}$ cells isolated from transgenic D011.10 mice, stained with proliferation dye (eFluor ${ }^{\mathrm{TM}}$ 670) on day 0 and were epicutaneously treated with OVA on shaved back on days 1, 2 and 3.

D) Macroscopic assessment of skin inflammation on day 5. Left: representative images of back skin, right: dermatitis score (see Fig. S5), $n=5$ for controls. Means $\pm S D, * p<0.05$.

E) Proliferative response and IL-4 expression of donor D011.10 cells. Frequency (left) of proliferating transgenic cells (see Fig. S5 for gating) in total $\mathrm{CD} 4^{+} \mathrm{T}$ cells, (middle left) total number of proliferating transgenic cells in the draining LNs and (middle right) and frequency of IL-4 transcriptional reporter (4get) expressing cells among $\mathrm{CD}^{+}{ }^{+}$cells of the draining LN and their absolute numbers (right) (see Fig. $\mathrm{S} 5$ for gating). $\mathrm{N}=5$ mice both groups with $2 \mathrm{LNs}$ analysed per mouse, means $\pm S D, * p<0.05, * * p<0.01$. Data representative of two experiments.

\section{Figure S5}

A) Gating of proliferating and IL-4-expressing OVA-specific transgenic D011.10 donor T cells in skin draining lymph node upon epicutaneous OVA administration.

B) Eczema severity score used to macroscopically quantify dermatitis in BALB/C $\mathrm{Flg}^{-/}$and control recipients of OVA-specific transgenic DO11.10 T cells epicutaneously treated with OVA (main Figure 5D).

\section{Figure 6}

Unexpected presence of the Tmem $79^{m a}$ gene variant in the $F / g^{f t / f t} \mathrm{BALB} / \mathrm{C}$ congenic strain An accurate sequence of BALB/C chromosome 3 was generated by whole genome long read single molecule real-time sequencing (PacBio) of our new BALB/C Flg ${ }^{-/}$strain and de novo assembly. In parallel, the $F / g^{f t / f t}$ BALB/C congenic strain (Saunders et al., 2016) was sequenced and chromosome 3 sequences of the two strains were compared. The two strains differ by a congenic interval of approximately $51.3 \mathrm{MB}$ that is made up by a C57BL/6- and a $\mathrm{C} 3 \mathrm{H}$-derived region, the latter containing $\mathrm{Flg}$ and Tmem79. As expected, the Flg gene of the $F / g^{f t / f t}$ BALB/C congenic strain (Saunders et al., 2016) harbors the $F g^{f t}$ mutation (1bp deletion in Flg repeat 6) while our BALB/C Flg ${ }^{-/}$strain carries an 8122 bp (out-of-frame) deletion in Flg 
exon 3. Unexpectedly, the Flgt/ft BALB/C congenic strain (Saunders et al., 2016) is homozygous for the atopy-associated $T m e m 79^{m a}$ mutation that was reported to be crossed out of this strain before initiation of backcrossing to BALB/c (Saunders et al., 2013). EDC, epidermal differentiation cluster.

\section{Table S1}

Genes located in the congenic interval of $F / g^{f t / f t}$ BALB/C congenic mice showing deleterious or structurally/functionally relevant differences between $\mathrm{Flg}^{\mathrm{ft} / \mathrm{ft}} \mathrm{BALB} / \mathrm{C}$ congenics and BALB/C mice. 'Deleterious': gain or loss of Stop codon, loss of a Start codon, frame shift, loss of splice site; 'potentially damaging': damaging missense mutations as predicted by SIFT. Numbers in brackets indicate numbers of individual potentially damaging mutations present in respective genes.

\section{Material and methods}

Mice:

Animals were kept under specific pathogen-free conditions (SPF) in individually ventilated cages (IVCS) at the Experimental Centre, Medical Faculty Carl-Gustav Carus, Technische Universität Dresden. Pathogen-free conditions were regularly tested according to the Federation for Laboratory Animal Science (FELASA). All animal experiments were done according to the German animal welfare law approved by the Landesdirektion Dresden (ref. no. DD25-5131/474/24) Wt BALB/c mice were obtained from Janvier. Flg ${ }^{f t / f t}$ BALB/c congenic mice were kept at Trinity College Dublin and genotype for mutations in $\mathrm{Flg}^{f t}$ (5303delA) and

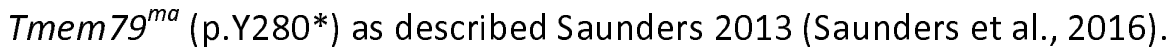

\section{Generation and genotyping of $\mathrm{Flg}^{-/}$mice on a pure BALB/C background}

Zygotes were isolated from superovulated female BALB/c mice at E0.5. 526 single zygotes were microinjected with Cas9 RNPs prepared from 5,25 $\mu \mathrm{M}$ NLS-Cas9 (Toolgen), 1,73 $\mu \mathrm{M}$ crRNA1 (unique target site: 5' GCTGGCAAAAGCATATTATG-3'), 1,73 $\mu \mathrm{M}$ crRNA2 (target site in each of the Flg repeat regions: 5' GTCAGCGCAAGATCAGGCTC-3') and 6,9 $\mu \mathrm{M}$ tracrRNA (all IDT). 187 embryos developed to the two-cell stage and were transferred into pseudopregnant foster mothers. Genotyping of $\mathrm{Flg}^{-1}$ mice was performed by PCR. Primers were designed to bind the BALB/C Flg gene in the non-repetitive region of exon 3 (For 5'CCAGATGACCAAGACATCGCTG 3' and Rev1 5'CTCTGGGTCTTCTGTTTCCCTCTC 3') or the Flg repeat regions (Rev2 5' GGCCCTGTGCTTGGCCTTG 3') (Fig S1).

\section{Western blot analysis}

Ears and tail skin were collected from 8 week-old mice and minced. Protein extraction was performed by $1 \mathrm{~h}$ incubation at $95^{\circ} \mathrm{C}$ in lysis buffer (6\% SDS, 30\% glycerol, $10 \mathrm{mM}$ DTT, bromophenol blue) agitation. Upon SDS-PAGE, transfer to nitrocellulose membrane (Amersham $^{\mathrm{TM}}$ Protran $^{\circledR}$ Premium $0.45 \mu \mathrm{m} \mathrm{NC}$ ) and blocking (5\% BSA/TBST, 2h at RT), membranes were incubated with primary antibodies for $1 \mathrm{~h}$ at RT with shaking (1:2000 antifilaggrin clone Poly19058, Biolegend; 1:2000 anti- $\beta$-actin, clone 13E5, Cell Signaling Technology). After washing ( $3 \times 5 \mathrm{~min}$ in Tris-buffered saline containing $0.1 \% \mathrm{v} / \mathrm{v}$ Tween 20 , with shaking), primary antibody was detected with alkaline phosphatase-conjugated 
polyclonal goat anti-rabbit IgG, D0487, Dako Denmark A/S) and alkaline phosphatase substrate (NBT/BCIP, Roche).

\section{Filaggrin immunofluorescence staining:}

Tail skin was fixed in 4\% PFA, paraffin-embedded and cut into $5 \mu \mathrm{M}$ sections. Slides were heat treated for 20 minutes at 70? $C$, followed by deparaffinization and rehydration. Sections were permeabilized by $0.1 \%$ Triton X-100/PBS treatment (10 min, RT), followed by washing. All washing was by incubating the slides 3 times in PBST Buffer for 5 min. Slides were blocked in $5 \%$ goat serum/PBST, for $1 \mathrm{~h}$ at RT, with agitation, followed by incubation for $1 \mathrm{~h}$ at $\mathrm{RT}$ in a 1:1000 dilution in blocking buffer of primary $A b$ (purified anti-Filaggrin polyclonal $A b$, clone Poly19058, Biolegend). After washing, slides were incubated for $1 \mathrm{~h}$ at RT in a 1:500 dilution of secondary Ab (IgG Highly Cross-Adsorbed Goat anti-Rabbit, Alexa Fluor ${ }^{\circledR} 488$, Invitrogen ${ }^{\mathrm{TM}}$ ). After the final wash, slides were mounted with mounting medium (Dako Fluorescence Mounting Medium, Dako North America, Inc.) containing $10 \mu \mathrm{g} / \mathrm{ml}$ of DAPI. Slides were analyzed on a LSM confocal microscope Zeiss LSM880 with AIRYscan.

\section{Quantification of transepidermal water loss (TEWL)}

Mice that had been shaved on their back 24h earlier were anesthetized (Ketamin/Xylazin) and TEWL was measured using an MDD4 device (CK electronic) according to the manufacturer's instructions. Each value was acquired as a mean of three individual measurements.

\section{Sorting of basal ear skin keratinocytes for RNA extraction}

Ears were minced in $1 \mathrm{ml}$ of DMEM/20mM Hepes buffer, and $0.5 \mathrm{~mL}$ of an enzyme mixture containing Liberase $\left(25 \mu \mathrm{g} / \mathrm{ml}\right.$, Liberase ${ }^{T m}$ Research Grade, Sigma Aldrich), Hyaluronidase $(0.5$ $\mathrm{mg} / \mathrm{ml}$ Sigma, 100mg Hyaluronidase from bovine testes, Sigma Aldrich), and DNasel (200U/ $\mu$ l, DNase I grade II, from bovine pancreas, Sigma Aldrich) was added, followed by incubation for $1 \mathrm{~h}$ at 37? $\mathrm{C}$ with agitation (1300rpm). Disassociated tissue was filtered through a $100 \mu \mathrm{m}$ mesh, washed with $5 \mathrm{ml}$ of cold FACS buffer (0.5\% BSA/2mM EDTA/PBS), and pelleted by centrifugation at $1200 \mathrm{rpm}$ for $5 \mathrm{~min}$ at 4 [C. Cells were resuspended in $75 \mu \mathrm{L}$ of FC blocking medium ( $5 \mu \mathrm{g} / \mathrm{ml}$ Purified anti-mouse CD16/32 Antibody, Biolegend in FACS buffer), and incubated for 20 minutes on ice. After centrifugation, cells were resuspended in $75 \mu \mathrm{l}$ of FACS buffer containing surface staining antibodies, and incubated on ice for $45 \mathrm{~min}$. Antibodies used for the staining are anti-mouse CD45 (PerCP-Cy5.5 labelled, clone 30-F11, eBioscience), anti-mouse CD11b (FITC labelled, clone M1/70, eBioscience), anti-mouse F4/80 (APC labelled, clone BM8, eBioscience), anti-mouse CD49f (PE labelled, clone eBioGoH3, eBioscience). After washing, stained cells were resuspended in FACS buffer containing $1 \mu \mathrm{g} / \mathrm{ml}$ of DAPI and kept on ice. Cell sorting of DAPI low/CD45-/CD49f ${ }^{+}$cells was performed on a BD FACSAria ${ }^{\mathrm{TM}}$ III instrument, using an $85 \mu \mathrm{M}$ nozzle. Conflicting events were excluded from the sort (purity sorting). Cells were sorted directly into a lysis buffer $(500 \mu \mathrm{l}$ of Buffer RLT Plus containing $\beta$-mercaptoethanol, Qiagen), and stored at -80 ? $\mathrm{C}$ before proceeding with RNA extraction.

RNA was extracted using RNeasy ${ }^{\circledR}$ Plus Micro Kit (Qiagen) according to the manufacturer's instructions and stored at $-80^{\circ} \mathrm{C}$. The quality of the isolated RNA was determined on a Bioanalyzer instrument (Agilent Technologies, Eukaryote Total RNA Pico chip). Samples with RNA integrity number higher than 7 were selected for RNA sequencing. mRNA libraries were subjected to sequencing on an Illumina ${ }^{\circledR} \mathrm{HighSeq}$ platform yielding 30 - 60 million reads per 
sample. Raw reads were mapped to the mouse genome $(\mathrm{mm} 10)$ and splice-site information from Ensembl release 87 (Zerbino et al., 2018) with gsnap (version 2018-07-04; (Wu and $\mathrm{Nacu}, 2010)$. Uniquely mapped reads and gene annotations from Ensembl were used as input for featureCounts (version 1.6.2; (Liao et al., 2014)) to create counts per gene. RNAseq differential expression analysis was performed with the $R$ package DESeq2 (Love et al., 2014).

\section{quantitative RT-PCR}

Total RNA from sorted CD45-negative cells was isolated using RNeasy ${ }^{\circledR}$ Plus Micro Kit (Qiagen), while RNA from whole ear skin tissue was extracted using RNeasy ${ }^{\circledR}$ Mini Kit (Qiagen), according to the manufacturer's instructions. cDNA was synthesized using the PrimeScript RT Reagent Kit (Takara). Quantification of transcripts was performed on a Mx3005P QPCR system (Agilent Technologies) for the IL-1b expression assay, using Maxima SYBR green/ROX qPCR Master Mix (Thermo Fisher Scientific). Quantification of all other transcriptos was performed using the Luna ${ }^{\circledR}$ Universal qPCR Master Mix (New England BioLabs), on a CFX384 ${ }^{\mathrm{TM}}$ Real-Time System (BIO-RAD). The following primers were used: $11-1 b$ Forward: 5'TGTGCAAGTGTCTGAAGCAGC3', Reverse: 5'TGGAAGCAGCCCTTCATCTT 3'. Cd74 Forward: $\quad 5^{\prime}$ CACCACTGCTTACTTCCTGTACCAG 3', Reverse: 5'GGTCATGTTGCCGTACTTGGTAACG 3'. H2-aa Forward: 5' CAAGGTGGAGCACTGGGGC 3', Reverse: 5' CTGACATGGGGGCTGGAATCTCAG 3'. Retnla Forward: 5' GGCGTATAAAAGCATCTCATCTGGC 3', Reverse: 5'GAGAGTCTTCGTTACAGTGGAGGG 3'. All samples were run in triplicates. qRT-PCR data are displayed as fold change compared to means of the respective control groups \pm SD.

\section{Staining for flow cytometry}

Preparation of single cell suspensions from skin and staining for extracellular markers were performed as described for Sorting of ear skin keratinocytes (see above). Antibodies used in different staining mixtures are anti-mouse CD45 (PerCP-Cy5.5 conjugated, clone 30-F11, eBioscience), anti-mouse CD326 (EpCAM) (APC conjugate, clone G8.8, eBioscience), antimouse $\gamma \delta T C R$ (FITC conjugated, clone eBioGoH3, eBioscience), anti-mouse CD86 (APC/Cy7 conjugated, clone GL1, Biolegend), anti-mouse CD3e (PE/Cy7 conjugated, clone 145-2C11, eBioscience), anti-mouse FCERI (APC-conjugated, clone MAR-1, Invitrogen), anti-mouse Siglec-F (PE conjugated, clone E50-2440, BD Biosciences), anti-mouse Gr-1 (PerCP-Cy5.5 conjugated, clone RB6-8C5, eBioscience), anti mouse CD117 (biotin conjugated, clone 2B8, eBioscience), anti-mouse CD25 (PE conjugated, clone PC61.5, eBioscience), anti-mouse CD278/ICOS (PE/Cy7 conjugated, C398.4A, Biolegend), anti-mouse CD127/IL-7Ra (APC conjugated, clone SB-199, Biolegend), anti-mouse CD90.2 (Super Bright 780, clone 30-H12, Invitrogen), anti-mouse CD11C (biotin conjugated, clone N418, eBioscience). For the detection of biotin conjugated antibodies, either SA-V500 (BD Biosciences) or SA-PE/Cy7 (Biolegend) were used. FlowJo (TreeStar, Ashland, Ore) was used for data analysis.

\section{OVA model and skin scoring.}

Analysis of DO11.10 $/ 4$ get transgenic T cell response to epicutaneous OVA immunization D011.10 $/$ 4get (Murphy et al., 1990) splenocytes were incubated with CD4 (L3T4) MicroBeads (Miltenyi) and separated using LS Columns (Miltenyi) by positive selection. Isolated T cells were labelled with Cell Proliferation Dye efluor ${ }^{\mathrm{TM}} 670$ (eBiosceince) according 
to the manufacturer's instructions. $2 \times 10^{6}$ labelled transgenic T cells were resuspended in 100 $\mu \mathrm{l}$ of PBS and adoptively transferred into recipient mice by i.v. injection. $24 \mathrm{~h}$ later, mice were epicutaneously immunized by painting $200 \mu \mathrm{l}$ of $1 \mathrm{mg} / \mathrm{ml}$ OVA/PBS solution onto the shaved back. This was repeated 2 more times at daily intervals. $48 \mathrm{~h}$ after the last treatment, mice were sacrificed and single cell suspensions of inguinal LNs obtained by crushing the LNs between two glass slides, rinsing with $2 \mathrm{ml}$ of cold FACS buffer (0.5\% BSA/2mM EDTA/PBS) and straining through $100 \mu \mathrm{M}$ mesh. After centrifugation (1200 rpm, $5 \mathrm{~min}, 4$ ? $\mathrm{C}$ ), cell pellets were resuspended in $75 \mu \mathrm{l}$ of $\mathrm{Fc}$ blocking buffer $(5 \mu \mathrm{g} / \mathrm{ml}$ Purified anti-mouse CD16/32 Antibody, Biolegend, in FACS buffer) and incubated on ice for 20 min. After pelleting, cells were resuspended in $75 \mu \mathrm{l}$ of FACS buffer containing anti-mouse CD4 (biotin conjugated, clone GK1.5, eBioscience) and anti-D011.10 Ab (PE conjugated, clone KJ1-26, Miltenyi) and incubated on ice for $45 \mathrm{~min}$.

Biotin detection was with SA-APC-Cy7 (Biolegend). After final washing, cells were resuspended in $200 \mu \mathrm{l}$ of cold FACS buffer containing $1 \mu \mathrm{g} / \mathrm{ml}$ DAPI. Samples were analysed on a BD FACSAria ${ }^{\text {TM }}$ III instrument. FlowJo (TreeStar, Ashland, Ore) was used for data analysis.

\section{Quantification of total and antigen-specific IgE}

Total mouse serum IgE levels were measured using the ELISA MAX ${ }^{\mathrm{TM}}$ Standard Set Mouse IgE kit (BioLegend) according to manufacturer's instructions. All individual standards and mouse serum samples were analysed in triplicates, with means of triplicates displayed in graphs. For analysis of OVA-specific serum IgE, 96-well MaxiSorp ELISA plates (Nunc, Roskilde, Denmark) were coated with $2 \mu \mathrm{g} / \mathrm{ml}$ of OVA solution in carbonate buffer and ELISA was performed using the ELISA MAX'M Standard Set Mouse IgE kit (BioLegend).

\section{Skin microbiome analysis}

DNA was extracted from cheek skin swab samples using the QIAamp ${ }^{\circledR}$ DNA Mini Kit (QIAGEN $\mathrm{GmbH}$, Hilden, Germany) as specified by the manufacturer for isolation of DNA from Grampositive bacteria with modifications. $180 \mu \mathrm{L}$ lysozyme $(20 \mathrm{mg} / \mathrm{mL})$ was used during for first lysis at $37^{\circ} \mathrm{C}$ for $30 \mathrm{~min} .20 \mu \mathrm{L}$ of proteinase $\mathrm{K}$ and $200 \mu \mathrm{L}$ of buffer $\mathrm{AL}$ and lysis for $10 \mathrm{~min}$ omitting the $15 \mathrm{~min}$ incubation at $95^{\circ} \mathrm{C}$. DNA quantity and quality were analyzed using a NanoDrop 1000 spectrophotometer (Thermo Fisher Scientific Germany BV \& Co KG, Braunschweig, Germany). Negative controls were performed for each extraction batches. DNA was amplified using universal bacterial primers $515 \mathrm{~F}$ and $806 \mathrm{R}$ targeting the $\mathrm{V} 4$ region of the 16S rRNA gene ((PMID: 22402401)). The primers were modified to include a unique barcode and Illumina primer sequences (P5 and P7). PCR was performed as previously described, including negative control and positive controls (mock community, HM-782D) (Schoilew et al., 2019). Libraries were prepared by PCR with 5 cycles using home-made primers combining the Illumina sequencing primers and the Illumina sequencing adapters and then purified using Agencourt AMPure XP beads (Beckman Coulter, Germany) following the manufacturer's instructions. Purified products were checked for quality and concentration using Quant-iT ${ }^{\mathrm{TM}}$ PicoGreen ${ }^{\circledR}$ dsDNA Assay Kit (ThermoFisher scientific GmbH, Dreieich, Germany) and Qiaxcel instrument (QIAGEN GmbH, Hilden, Germany). An equimolar mix of all the PCR products was then sequenced on an Illumina ${ }^{\circledR}$ MiSeq instrument (V3 chemistry).

\section{Whole genome sequencing}


High molecular weight genomic DNA (gDNA) was extracted from snap-frozen spleen of $\mathrm{Flg}$ ft/ft BALB/C congenics (Saunders et al., 2016) and BALB/C Flg ${ }^{-/-}$mice following the Animal Tissue DNA Isolation Kit (bionano genomics) following the manufacturer's protocol for soft tissues. In brief, spleen tissue was homogenized and fixed on ice in a tissue grinder, followed by embedding in agarose plugs and proteinase $\mathrm{K}$ and RNase treatment of the plugs. Genomic DNA was recovered from plugs by agarase treatment and purified by drop dialysis against $1 x$ TE buffer. Integrity of high molecular weight gDNA was determined by pulsed-field gel electrophoresis using the Pippin Pulse ${ }^{\mathrm{TM}}$ device (Sage Science). Most of the gDNA was larger than $300 \mathrm{~kb}$ in length. The gDNA was further purified with $1 \mathrm{x}$ volume AMPure XP beads (Beckman Coulter) following the manufacturer's instructions. Long insert libraries were prepared using the SMRTbell Express Template Prep Kit 2.0 (Pacific Biosciences) following the manufacturer's instructions. In brief, gDNA was sheared using the MegaRuptor ${ }^{\mathrm{TM}}$ device (Diagenode). $10 \mu \mathrm{g}$ ( $\mathrm{Flg}{ }^{\mathrm{ft} / \mathrm{ft}}$ BALB/C congenic) and $18 \mu \mathrm{g}$ (BALB/c $\mathrm{Flg}^{-/}$) of sheared gDNA were used for PacBio SMRTbell ${ }^{\mathrm{TM}}$ library preparation. The libraries were subjected to size selection (about $15 \mathrm{~kb}$ ) using the BluePippin ${ }^{\mathrm{TM}}$ instrument (Sage Science). Fractions were purified with 0,6x AMPure XP beads, and checked for their final size on the fragment analyzer (Agilent). The size selected library was loaded with 50 and $55 \mathrm{pM}$ on plate on two Sequel SMRT cells (8M) each, sequencing primer v2 was used with the Sequel polymerase 2.0 and the Sequel sequencing kit 2.0, pre-extension time was 2 hours and run time was 30 hours for all SMRT cells. A total of 3 SMRT cells was sequenced for the $F / g^{f t / f t}$ BALB/C congenics leading to a total yield of $43,6 \mathrm{~Gb}$ ccs reads and a total of 2 SMRT cells has been sequenced for the BALB/C Flg ${ }^{-/}$strain with a total yield of $41.4 \mathrm{~Gb}$ circular consensus sequences resulting in $18 \mathrm{X}$ genome coverage for both strains.

We used PacBio's command line tool ccs (version 4.2.0, with default parameter, (https://github.com/PacificBiosciences/ccs)), that takes multiple subreads from the same SMRTbell molecule, to produce highly accurate long reads (HiFi reads). HiFi reads were generated for the three SMRT cells of the $\mathrm{Flg}^{\mathrm{ft} / \mathrm{ft}} \mathrm{BALB} / \mathrm{C}$ congenic strain and the two SMRT cells for the BALB/C Flg ${ }^{-/}$strain. The HiFi yield for the $\mathrm{Flg}^{\mathrm{ft} / \mathrm{ft}} \mathrm{BALB} / \mathrm{C}$ congenic strain was 45.7Gb (average read length $15.3 \mathrm{~Kb}$, coverage $16.2 \mathrm{X}$ ), and $41.4 \mathrm{~Gb}$ (average read length $13.9 \mathrm{~Kb}$, coverage $14.7 \mathrm{X}$ ) for the BALB/C $\mathrm{Flg}^{-/}$strain. Both HiFi read sets where assembled separately using the de novo assembler hifiasm with default parameters (version 0.7, https://github.com/chhylp123/hifiasm, https://arxiv.org/abs/2008.01237). The $F / g^{f t / f t}$ BALB/C congenic strain assembly has a total size of $2.62 \mathrm{~Gb}$ with $\mathrm{N} 50$ of $6.12 \mathrm{Mb}$ and 1373 contigs. The $\mathrm{Flg}^{-/-} \mathrm{BALB} / \mathrm{C}$ strain assembly has 1082 contigs with $\mathrm{N} 50$ of $6.5 \mathrm{Mb}$ and a total size of $2.59 \mathrm{~Gb}$. As the congenic region is located on chromosome 3 , the variation analysis was limited to contigs corresponding to chromosome 3 . We mapped all contigs to the mouse reference genome (GRCm38.p6) with minimap2 and separated the chromosome 3 contigs, resulting in 38 contigs. Gene annotation was performed by mapping the annotated mouse coding genes to the new assemblies. We generated liftOver chains by computing pairwise alignment chains to the mouse $\mathrm{GRCm} 38$ assembly using lastz (alignment parameters $\mathrm{K}=6000$, $\mathrm{L}=8000, \mathrm{Y}=3000, \mathrm{H}=2000$, default scoring matrix), axtChain (linearGap=loose, otherwise default parameters), chainNet and netChainSubset, as implemented in the UCSC genome browser script doBlastzChainNet.pl. We downloaded mouse GENCODE V25 genes from the UCSC genome browser table wgEncodeGencodeCompVM25 and used liftOver (https://genome.ucsc.edu/cgi-bin/hgLiftOver, parameter minMatch=0.8) to map the genes. For the variation analysis all HiFi reads (BALB/C Flg $g^{-/}$strain and $\mathrm{Flg}{ }^{\mathrm{ft} / \mathrm{ft}} \mathrm{BALB} / \mathrm{C}$ congenic strain) were mapped to the $\mathrm{BALB} / \mathrm{C} \mathrm{Flg}^{-/}$assembly using pbmm2 (version 1.2.1, https://github.com/PacificBiosciences/pbmm2/). To reduce ambiguous mappings, the 
alignments were further filtered by restricting a maximum number of soft-clipped bases to 1 . This resulted in two alignment files - one for the $F / g^{f t / f t} B A L B / C$ congenic reads and one for the $\mathrm{BALB} / \mathrm{C} \mathrm{Flg}^{-/}$reads. The HiFi mapped reads of the 38 chromosome 3 contigs were used for the variant analysis. We used freebayes (version v1.3.2-46-g2c1e395, https://github.com/ekg/freebayes, https://arxiv.org/abs/1207.3907) to detect small polymorphisms and pbsv (version: 2.3.0, https://github.com/pacificbiosciences/pbsv/) for structural variations. We filtered variants based on a quality score QUAL>20 to detect robust variants and those unique to reads of the $F / g^{f t / f t}$ BALB/C congenic strain to remove any sequencing or alignment errors. Finally, the Ensembl Variant Effect Predictor (VEP, version: 100.3, (McLaren et al., 2016)) was used to annotate variants predicted to have phenotypic impact based on the gene annotations. Using the filtered variant files and custom annotations (see above), we then listed those with either Deleterious or Potentially damagingpredicted effects. These were then inspected manually.

\section{Supplementary methods}

Pseudocode for programs that were used:

\section{Circular consensus sequence}

\# run ccs in 200 chunks to create HiFi ccs reads

ccs $\{$ inFile\} \{outFile\}.\{chunk\}.bam --chunk \{chunk\}/200 -j \{THREAD\}

\# merge chunks

samtools merge -@\{THREAD\} \{outFile\}.bam \{outFile\}.*.bam

\# create index file

pbindex \{outFile\}.bam

De novo assembly

\# de novo assembly of $f t$-reads

hifiasm -t 40 -p FT_ASM -I0 m54345U_200218_090903.fasta.gz m54345U_200226_133426.fasta.gz

m54345U_200302_163910.fasta.gz

\# de novo assembly of flg-reads

hifiasm -t 38 -p FLG_ASM -I0 m64046_200612_062832.ccs.fasta.gz m64046_200616_095232.ccs.fasta.gz

Gene annotation

$<$ todo $>$ Michael

Variation analysis

\# map CCS reads to flg assembly

pbmm2 align -j 24 -I 1000 -N 2 --strip --sort --preset CCS FLG_ASM.p_ctg.fasta m54345U_200218_090903.ccs.bam FLG_ASM.p.m54345U_200218_090903.bam

pbmm2 align -j 24 - I 1000 -N 2 --strip --sort --preset CCS FLG_ASM.p_ctg.fasta m54345U_200226_133426.ccs.bam FLG_ASM.p.m54345U_200226_133426.bam

pbmm2 align -j 24 -I 1000 -N 2 --strip --sort --preset CCS FLG_ASM.p_ctg.fasta m54345U_200302_163910.ccs.bam FLG_ASM.p.m54345U_200302_163910.bam

pbmm2 align -j 24 - I 1000 -N 2 --strip --sort --preset CCS FLG_ASM.p_ctg.fasta m64046_200612_062832.ccs.bam FLG_ASM.p.m64046_200612_062832.bam

pbmm2 align -j 24 -I 1000 -N 2 --strip --sort --preset CCS FLG_ASM.p_ctg.fasta m64046_200616_095232.ccs.bam FLG_ASM.p.m64046_200616_095232.bam

\# alignment filtering: restrict maximum number of soft-clipped bases to 1

for $x$ in FLG_ASM.p.*bam

do 
bioRxiv preprint doi: https://doi.org/10.1101/2020.09.11.293688; this version posted September 11, 2020. The copyright holder for this preprint (which was not certified by peer review) is the author/funder, who has granted bioRxiv a license to display the preprint in perpetuity. It is made available under aCC-BY 4.0 International license.

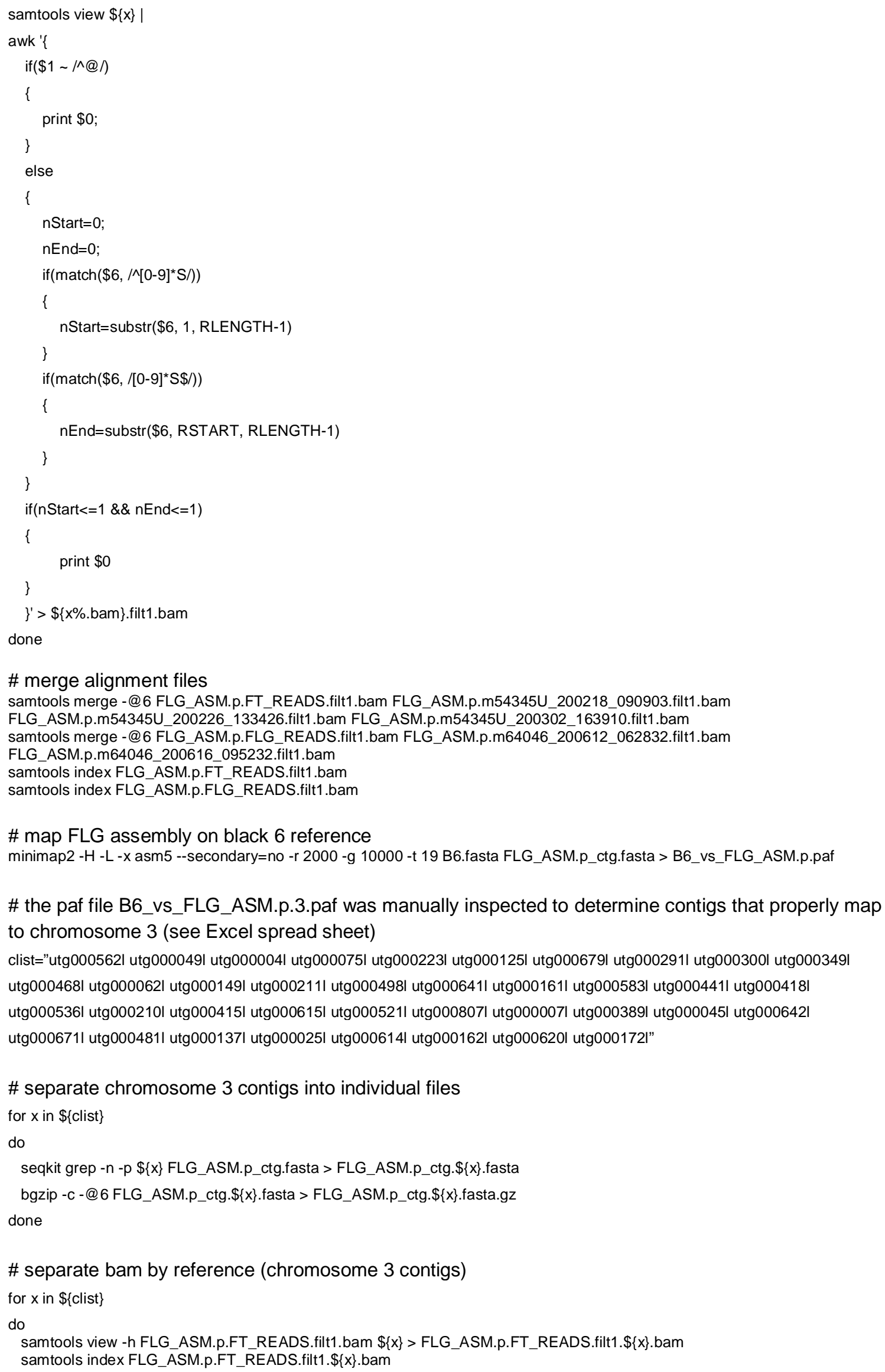


bioRxiv preprint doi: https://doi.org/10.1101/2020.09.11.293688; this version posted September 11, 2020. The copyright holder for this preprint (which was not certified by peer review) is the author/funder, who has granted bioRxiv a license to display the preprint in perpetuity. It is made available under aCC-BY 4.0 International license.

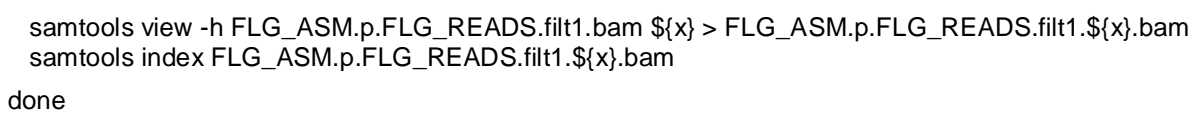


bioRxiv preprint doi: https://doi.org/10.1101/2020.09.11.293688; this version posted September 11, 2020. The copyright holder for this preprint (which was not certified by peer review) is the author/funder, who has granted bioRxiv a license to display the preprint in perpetuity. It is made available under aCC-BY 4.0 International license.

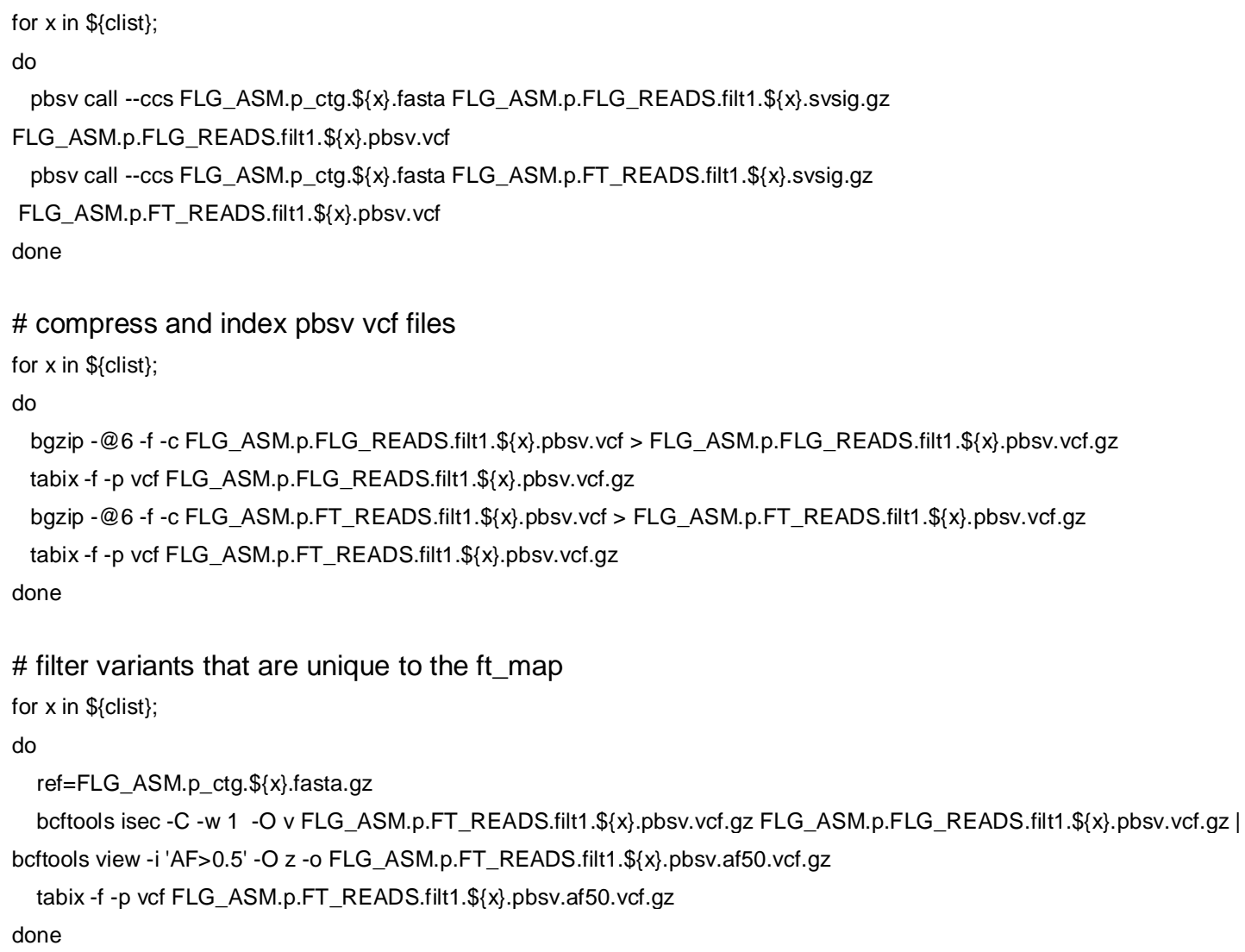

\section{Effect Prediction}

\# convert gene annotation into gff3 format

bedToGenePred genCode25.HLmusMusBal1.bed genCode25.HLmusMusBal1.genePred genePredToGtf file genCode25.HLmusMusBal1.genePred genCode25.HLmusMusBal1.gtf gffread -E genCode25.HLmusMusBal1.gtf -o- > genCode25.HLmusMusBal1.gff3

grep -v "\#" genCode25.HLmusMusBal1.gff3 | sort -k1,1 -k4,4n -k5,5n -t\$'lt' | bgzip -c > genCode25.HLmusMusBal1.gff3.gz tabix -p gff genCode25.HLmusMusBal1.gff3.gz

\section{\# run ensemble VEP on freebayes variants}

for $\mathrm{x}$ in $\$\{$ clist $\}$

do

ref=FLG_ASM.p_ctg. $\$\{x\} . f a s t a . g z$

var=FLG_ASM.p.FT_READS.filt1. $\$\{x\}$.freebayes.norm.q20.af90.vcf.gz

ann=genCode25.HLmusMusBal1.gff3.gz

vep -i \$(Schonhuber et al.) --dir_cache --fork ./ 9 --force_overwrite --fasta $\$\{r$ ref $\}$--custom $\$\{a n n\}, V E P \_01 \_\$\{x\}, g f f, o v e r l a p, 1$-o $\$\{$ ref\%.fasta.gz\}.VEP.freebayes.01.txt"

done

\# run ensemble VEP on pbsv structural variants

for $x$ in utg00*

do

ref=FLG_ASM.p_ctg. $\$\{x\} . f a s t a . g z$

var=FLG_ASM.p.FT_READS.filt1.\$\{x\}.pbsv.af50.vcf.gz

ann=genCode25.HLmusMusBal1.gff3.gz 


\footnotetext{
vep -i \$(Schonhuber et al.) --dir_cache --fork ./ 9 --force_overwrite --fasta $\$\{$ ref $\}$--custom $\$\{a n n\}, V E P \_01 \_\$\{x\}, g f f, o v e r l a p, 1-0$ $\$\{$ ref\%.fasta.gz\}.VEP.pbsv.01.txt" done
}

\section{References}

Bieber, T. (2008). Atopic dermatitis. N Engl J Med 358, 1483-1494.

Dickel, H., Gambichler, T., Kamphowe, J., Altmeyer, P., and Skrygan, M. (2010). Standardized tape stripping prior to patch testing induces upregulation of Hsp90, Hsp70, IL-33, TNF-alpha and IL-8/CXCL8 mRNA: new insights into the involvement of 'alarmins'. Contact Dermatitis 63, 215-222.

Eid, J., Fehr, A., Gray, J., Luong, K., Lyle, J., Otto, G., Peluso, P., Rank, D., Baybayan, P., Bettman, B., et al. (2009). Real-time DNA sequencing from single polymerase molecules. Science 323, 133-138.

Fallon, P.G., Sasaki, T., Sandilands, A., Campbell, L.E., Saunders, S.P., Mangan, N.E., Callanan, J.J., Kawasaki, H., Shiohama, A., Kubo, A., et al. (2009). A homozygous frameshift mutation in the mouse Flg gene facilitates enhanced percutaneous allergen priming. Nat Genet $41,602-$ 608.

Geoghegan, J.A., Irvine, A.D., and Foster, T.J. (2018). Staphylococcus aureus and Atopic Dermatitis: A Complex and Evolving Relationship. Trends Microbiol 26, 484-497.

Harris, T.A., Gattu, S., Propheter, D.C., Kuang, Z., Bel, S., Ruhn, K.A., Chara, A.L., Edwards, M., Zhang, C., Jo, J.H., et al. (2019). Resistin-like Molecule alpha Provides Vitamin-A-Dependent Antimicrobial Protection in the Skin. Cell Host Microbe 25, 777-788 e778.

Irvine, A.D., McLean, W.H., and Leung, D.Y. (2011). Filaggrin mutations associated with skin and allergic diseases. N Engl J Med 365, 1315-1327.

Kakkar, R., Hei, H., Dobner, S., and Lee, R.T. (2012). Interleukin 33 as a mechanically responsive cytokine secreted by living cells. J Biol Chem 287, 6941-6948.

Kawasaki, H., Nagao, K., Kubo, A., Hata, T., Shimizu, A., Mizuno, H., Yamada, T., and Amagai, M. (2012). Altered stratum corneum barrier and enhanced percutaneous immune responses in filaggrin-null mice. J Allergy Clin Immunol 129, 1538-1546 e1536.

Lane, P.W. (1972). Two new mutations in linkage group XVI of the house mouse. Flaky tail and varitint-waddler-J. J Hered 63, 135-140.

Liao, Y., Smyth, G.K., and Shi, W. (2014). featureCounts: an efficient general purpose program for assigning sequence reads to genomic features. Bioinformatics 30, 923-930.

Love, M.I., Huber, W., and Anders, S. (2014). Moderated estimation of fold change and dispersion for RNA-seq data with DESeq2. Genome Biol 15, 550.

Matsui, T., and Amagai, M. (2015). Dissecting the formation, structure and barrier function of the stratum corneum. Int Immunol 27, 269-280.

McLaren, W., Gil, L., Hunt, S.E., Riat, H.S., Ritchie, G.R., Thormann, A., Flicek, P., and Cunningham, F. (2016). The Ensembl Variant Effect Predictor. Genome Biol 17, 122. Mohrs, M., Shinkai, K., Mohrs, K., and Locksley, R.M. (2001). Analysis of type 2 immunity in vivo with a bicistronic IL-4 reporter. Immunity 15, 303-311.

Murphy, K.M., Heimberger, A.B., and Loh, D.Y. (1990). Induction by antigen of intrathymic apoptosis of CD4+CD8+TCRlo thymocytes in vivo. Science 250, 1720-1723.

Otsuka, A., Nomura, T., Rerknimitr, P., Seidel, J.A., Honda, T., and Kabashima, K. (2017). The interplay between genetic and environmental factors in the pathogenesis of atopic dermatitis. Immunol Rev 278, 246-262.

Palmer, C.N., Irvine, A.D., Terron-Kwiatkowski, A., Zhao, Y., Liao, H., Lee, S.P., Goudie, D.R., Sandilands, A., Campbell, L.E., Smith, F.J., et al. (2006). Common loss-of-function variants of 
the epidermal barrier protein filaggrin are a major predisposing factor for atopic dermatitis. Nat Genet 38, 441-446.

Presland, R.B., Boggess, D., Lewis, S.P., Hull, C., Fleckman, P., and Sundberg, J.P. (2000). Loss of normal profilaggrin and filaggrin in flaky tail (ft/ft) mice: an animal model for the filaggrindeficient skin disease ichthyosis vulgaris. J Invest Dermatol 115, 1072-1081.

Roan, F., Obata-Ninomiya, K., and Ziegler, S.F. (2019). Epithelial cell-derived cytokines: more than just signaling the alarm. J Clin Invest 129, 1441-1451.

Sandilands, A., Sutherland, C., Irvine, A.D., and McLean, W.H. (2009). Filaggrin in the frontline: role in skin barrier function and disease. J Cell Sci 122, 1285-1294.

Sandilands, A., Terron-Kwiatkowski, A., Hull, P.R., O'Regan, G.M., Clayton, T.H., Watson, R.M., Carrick, T., Evans, A.T., Liao, H., Zhao, Y., et al. (2007). Comprehensive analysis of the gene encoding filaggrin uncovers prevalent and rare mutations in ichthyosis vulgaris and atopic eczema. Nat Genet 39, 650-654.

Saunders, S.P., Floudas, A., Moran, T., Byrne, C.M., Rooney, M.D., Fahy, C.M.R., Geoghegan, J.A., Iwakura, Y., Fallon, P.G., and Schwartz, C. (2020). Dysregulated skin barrier function in Tmem79 mutant mice promotes IL-17A-dependent spontaneous skin and lung inflammation. Allergy.

Saunders, S.P., Goh, C.S., Brown, S.J., Palmer, C.N., Porter, R.M., Cole, C., Campbell, L.E., Gierlinski, M., Barton, G.J., Schneider, G., et al. (2013). Tmem79/Matt is the matted mouse gene and is a predisposing gene for atopic dermatitis in human subjects. J Allergy Clin Immunol 132, 1121-1129.

Saunders, S.P., Moran, T., Floudas, A., Wurlod, F., Kaszlikowska, A., Salimi, M., Quinn, E.M., Oliphant, C.J., Nunez, G., McManus, R., et al. (2016). Spontaneous atopic dermatitis is mediated by innate immunity, with the secondary lung inflammation of the atopic march requiring adaptive immunity. J Allergy Clin Immunol 137, 482-491.

Savinko, T., Matikainen, S., Saarialho-Kere, U., Lehto, M., Wang, G., Lehtimaki, S., Karisola, P., Reunala, T., Wolff, H., Lauerma, A., and Alenius, H. (2012). IL-33 and ST2 in atopic dermatitis: expression profiles and modulation by triggering factors. J Invest Dermatol 132, 1392-1400. Schonhuber, N., Seidler, B., Schuck, K., Veltkamp, C., Schachtler, C., Zukowska, M., Eser, S., Feyerabend, T.B., Paul, M.C., Eser, P., et al. (2014). A next-generation dual-recombinase system for time- and host-specific targeting of pancreatic cancer. Nat Med 20, 1340-1347. Schwartz, C., Moran, T., Saunders, S.P., Kaszlikowska, A., Floudas, A., Bom, J., Nunez, G., Iwakura, Y., O'Neill, L., Irvine, A.D., et al. (2019). Spontaneous atopic dermatitis in mice with a defective skin barrier is independent of ILC2 and mediated by IL-1beta. Allergy 74, 19201933.

Smith, F.J., Irvine, A.D., Terron-Kwiatkowski, A., Sandilands, A., Campbell, L.E., Zhao, Y., Liao, H., Evans, A.T., Goudie, D.R., Lewis-Jones, S., et al. (2006). Loss-of-function mutations in the gene encoding filaggrin cause ichthyosis vulgaris. Nat Genet 38, 337-342.

Sybert, V.P., Dale, B.A., and Holbrook, K.A. (1985). Ichthyosis vulgaris: identification of a defect in synthesis of filaggrin correlated with an absence of keratohyaline granules. J Invest Dermatol 84, 191-194.

Tamoutounour, S., Han, S.J., Deckers, J., Constantinides, M.G., Hurabielle, C., Harrison, O.J., Bouladoux, N., Linehan, J.L., Link, V.M., Vujkovic-Cvijin, I., et al. (2019). Keratinocyte-intrinsic $\mathrm{MHCll}$ expression controls microbiota-induced Th1 cell responses. Proc Natl Acad Sci U S A 116, 23643-23652.

Walley, A.J., Chavanas, S., Moffatt, M.F., Esnouf, R.M., Ubhi, B., Lawrence, R., Wong, K., Abecasis, G.R., Jones, E.Y., Harper, J.I., et al. (2001). Gene polymorphism in Netherton and common atopic disease. Nat Genet 29, 175-178. 
Weidinger, S., and Novak, N. (2016). Atopic dermatitis. Lancet 387, 1109-1122.

Wenger, A.M., Peluso, P., Rowell, W.J., Chang, P.C., Hall, R.J., Concepcion, G.T., Ebler, J., Fungtammasan, A., Kolesnikov, A., Olson, N.D., et al. (2019). Accurate circular consensus long-read sequencing improves variant detection and assembly of a human genome. Nat Biotechnol 37, 1155-1162.

Wu, T.D., and Nacu, S. (2010). Fast and SNP-tolerant detection of complex variants and splicing in short reads. Bioinformatics 26, 873-881.

Zerbino, D.R., Achuthan, P., Akanni, W., Amode, M.R., Barrell, D., Bhai, J., Billis, K., Cummins, C., Gall, A., Giron, C.G., et al. (2018). Ensembl 2018. Nucleic Acids Res 46, D754-D761. 
A exon2 exon3 $\quad$ near perfect $\mathrm{Flg}$ repeats

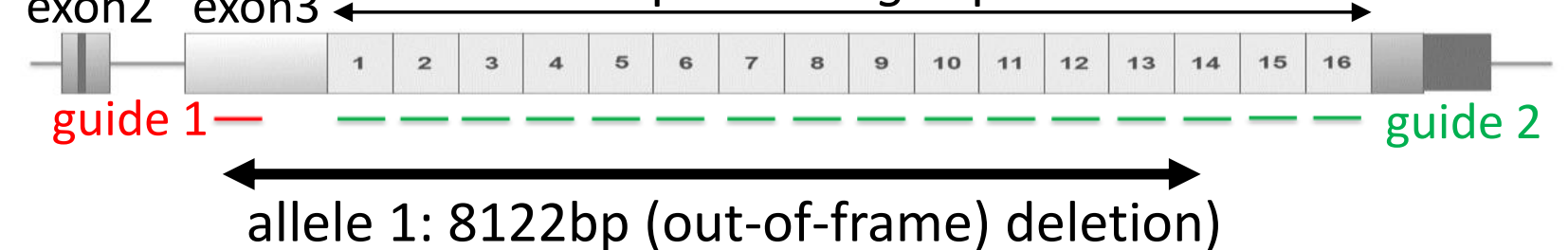

B

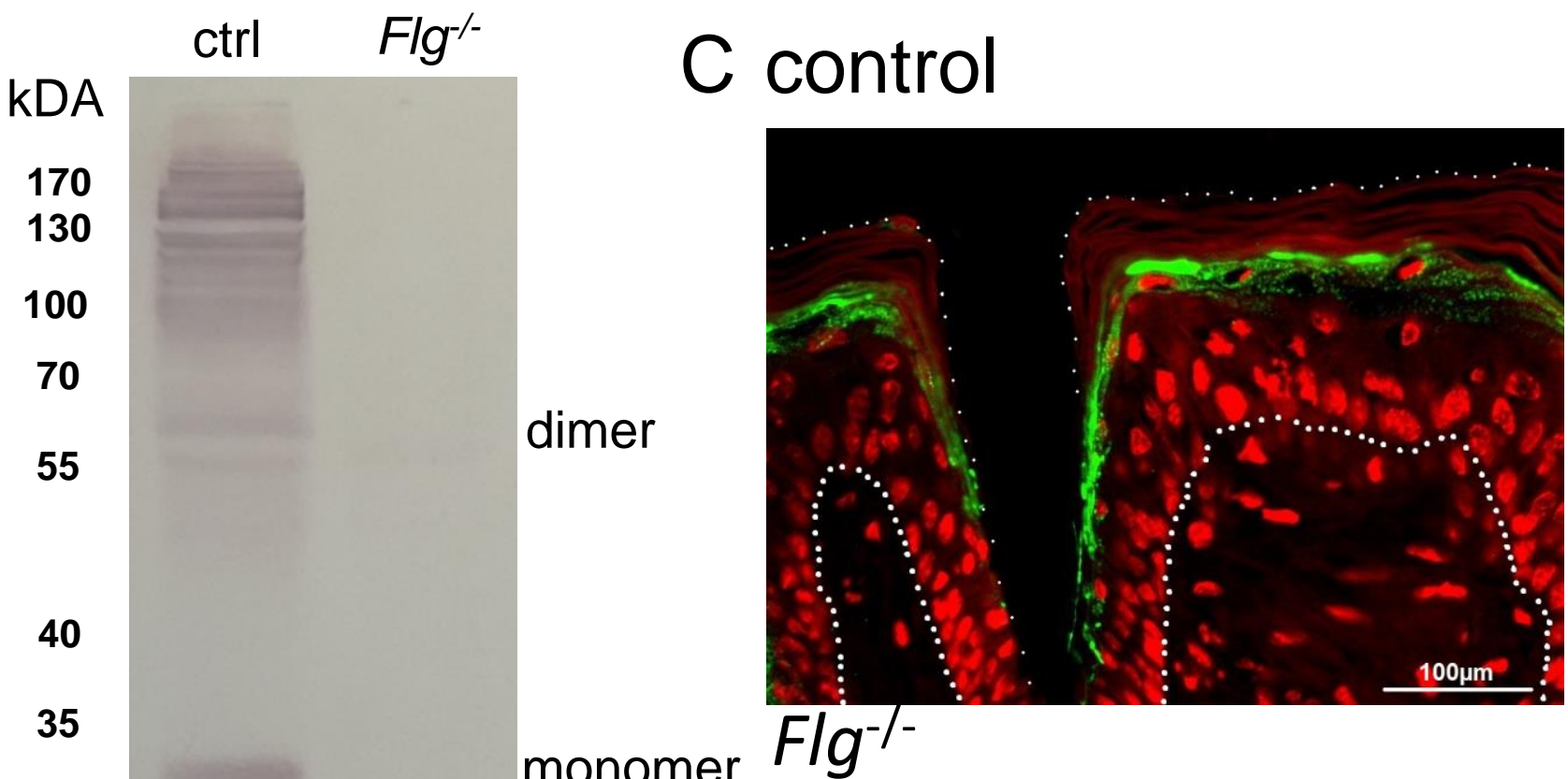

Figure 1

$\beta$-Act

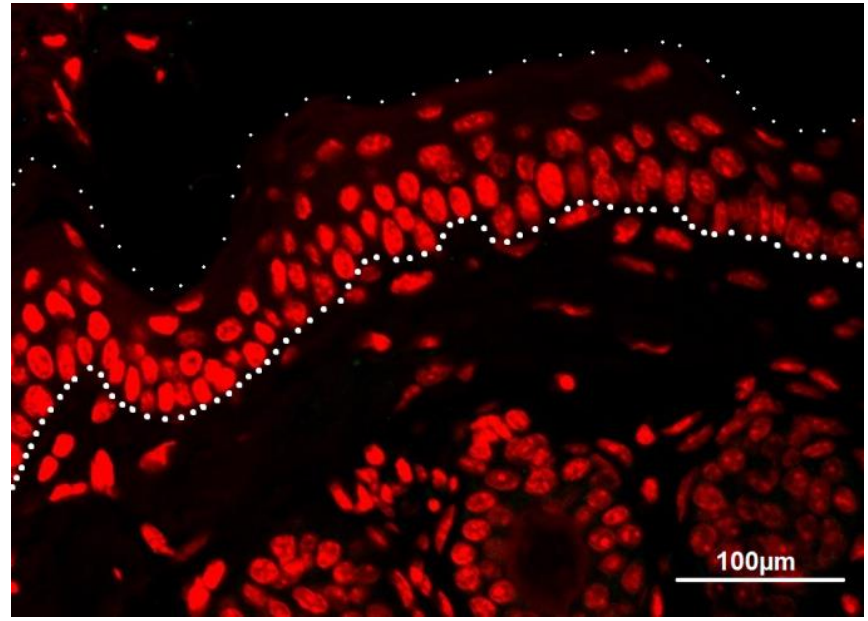




\section{A}

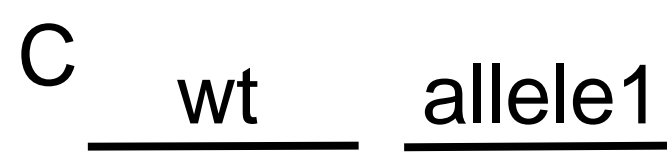

\begin{tabular}{|l|l|}
\hline micro-injected zygotes & 526 \\
\hline embryos transferred to foster mothers & 187 \\
\hline number of offspring born & 12 \\
\hline $\begin{array}{l}\text { founders with large deletions } \\
\text { detectable by PCR }\end{array}$ & 3 \\
\hline
\end{tabular}

B
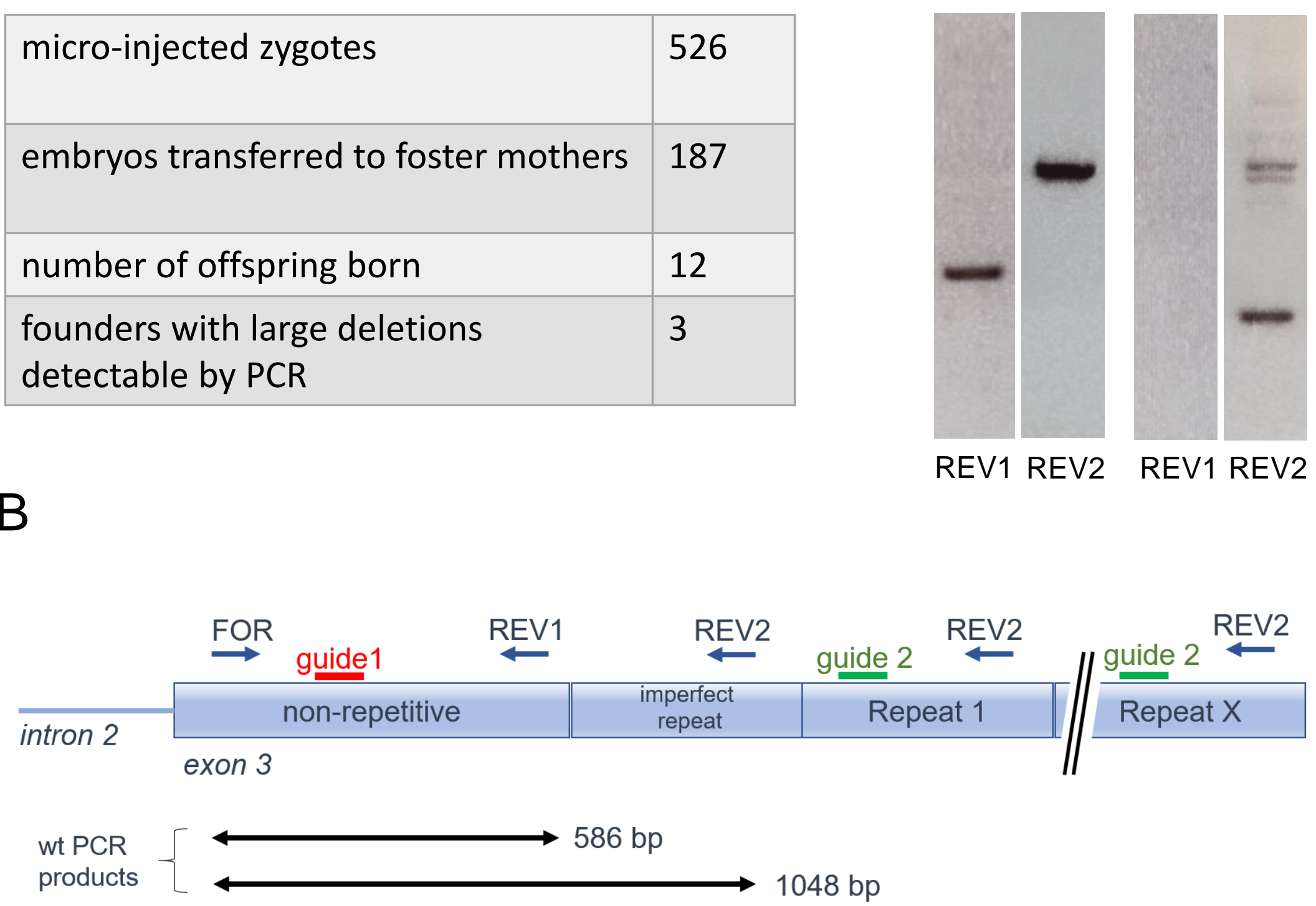

\section{Figure S1}




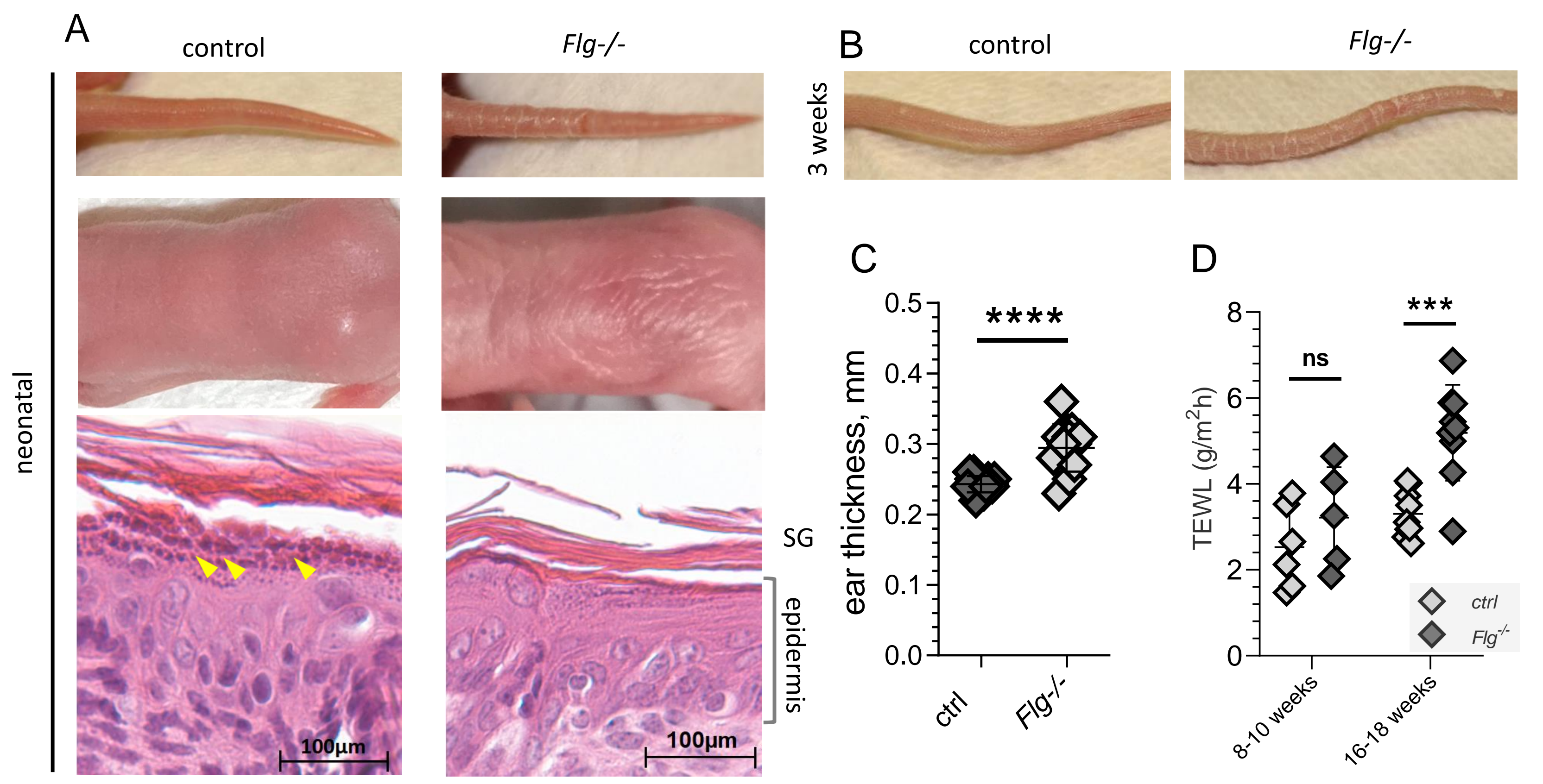

Figure 2 
control

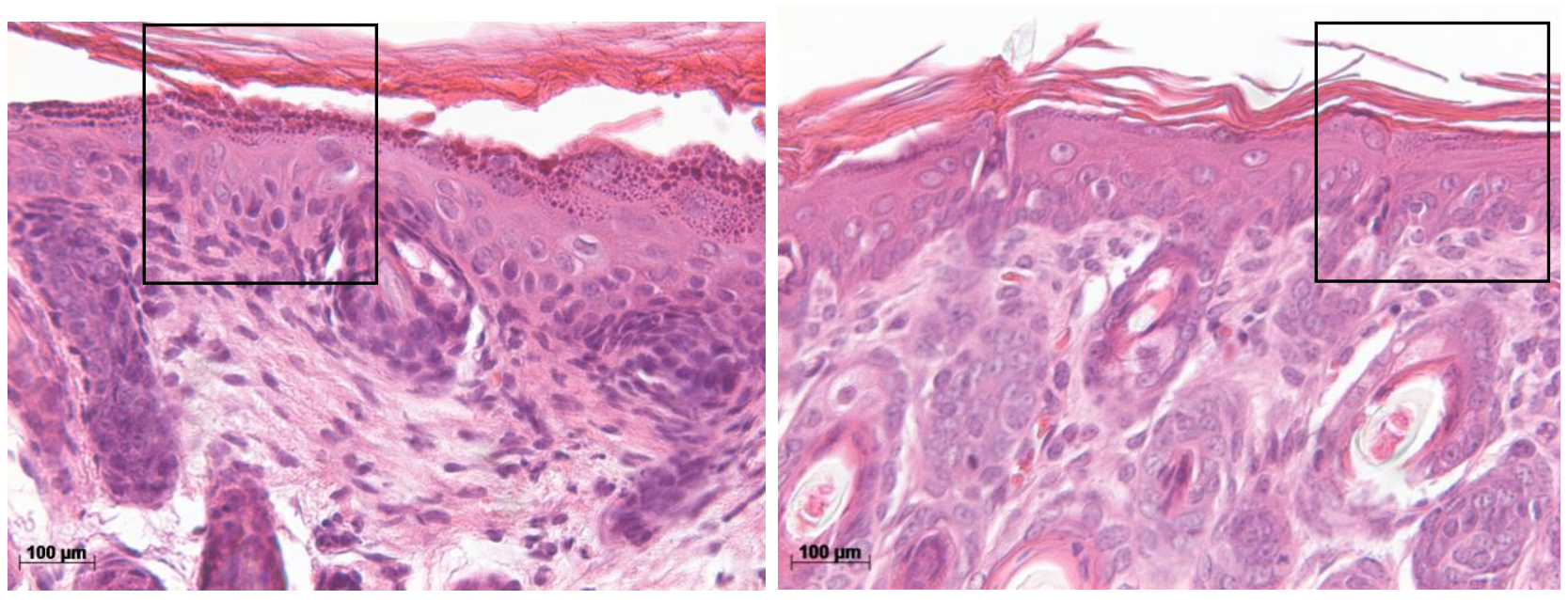

Flg-/-

Figure S2 
A

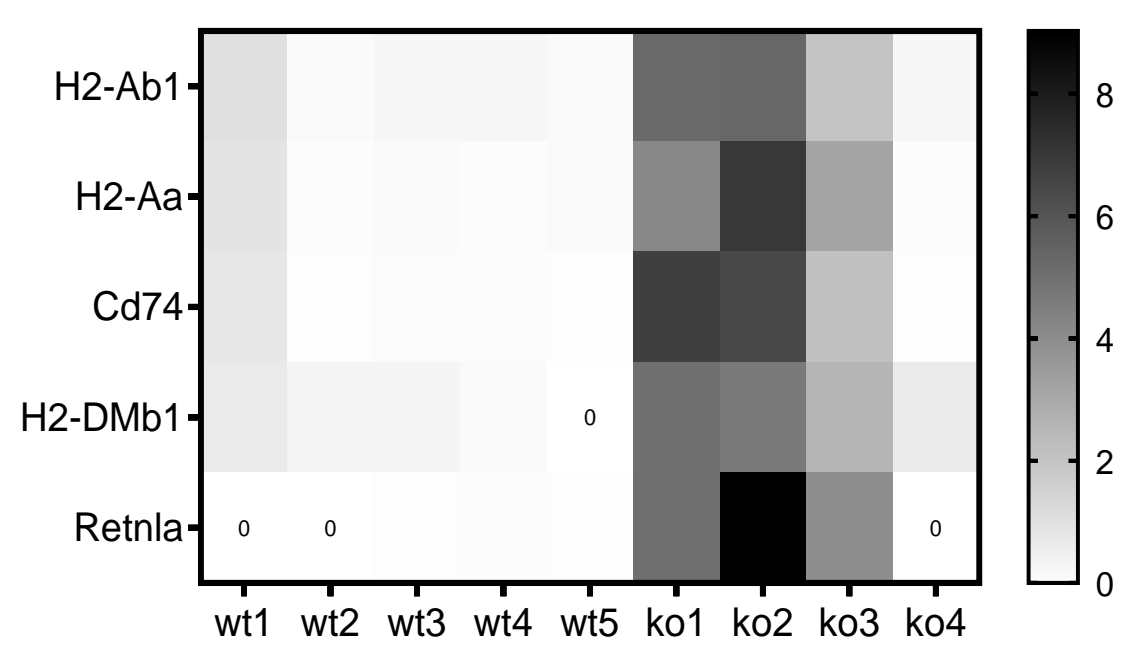

D

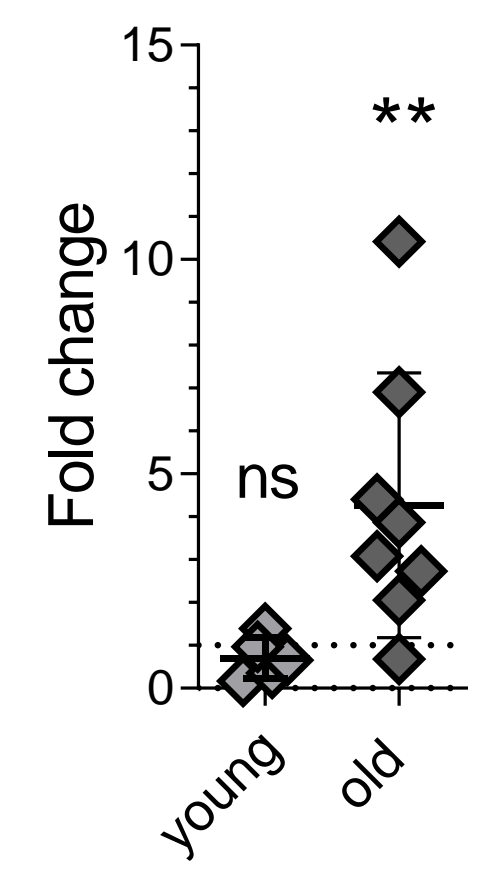

E

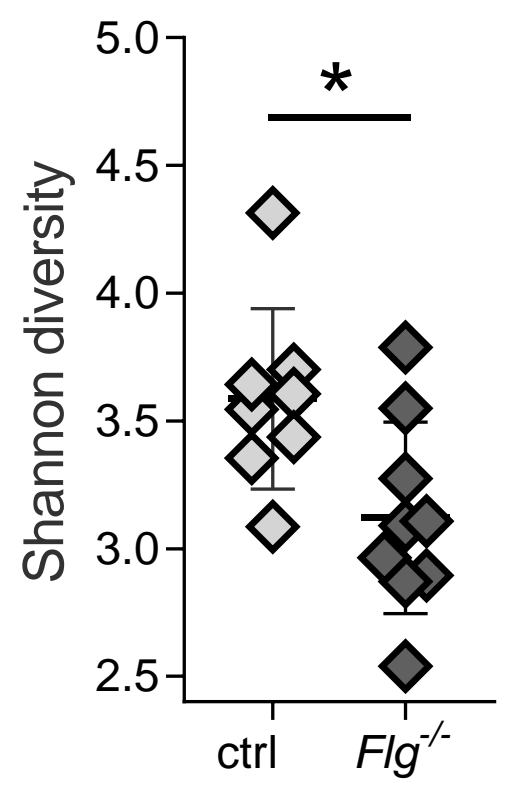

B
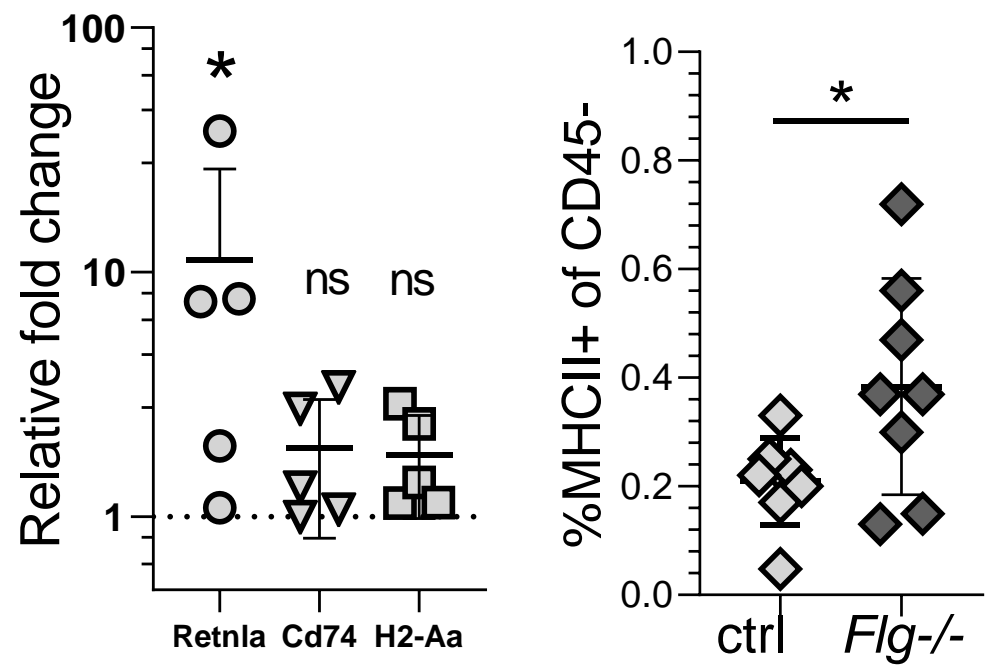

Family

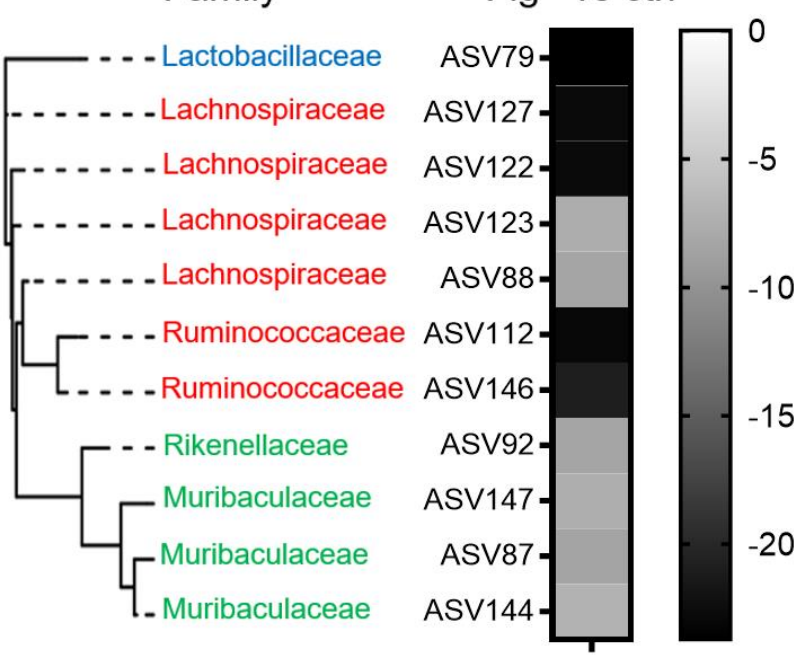

Bacterial order

Lactobacillales

Clostridiales

Bacteroidales

Figure 3 


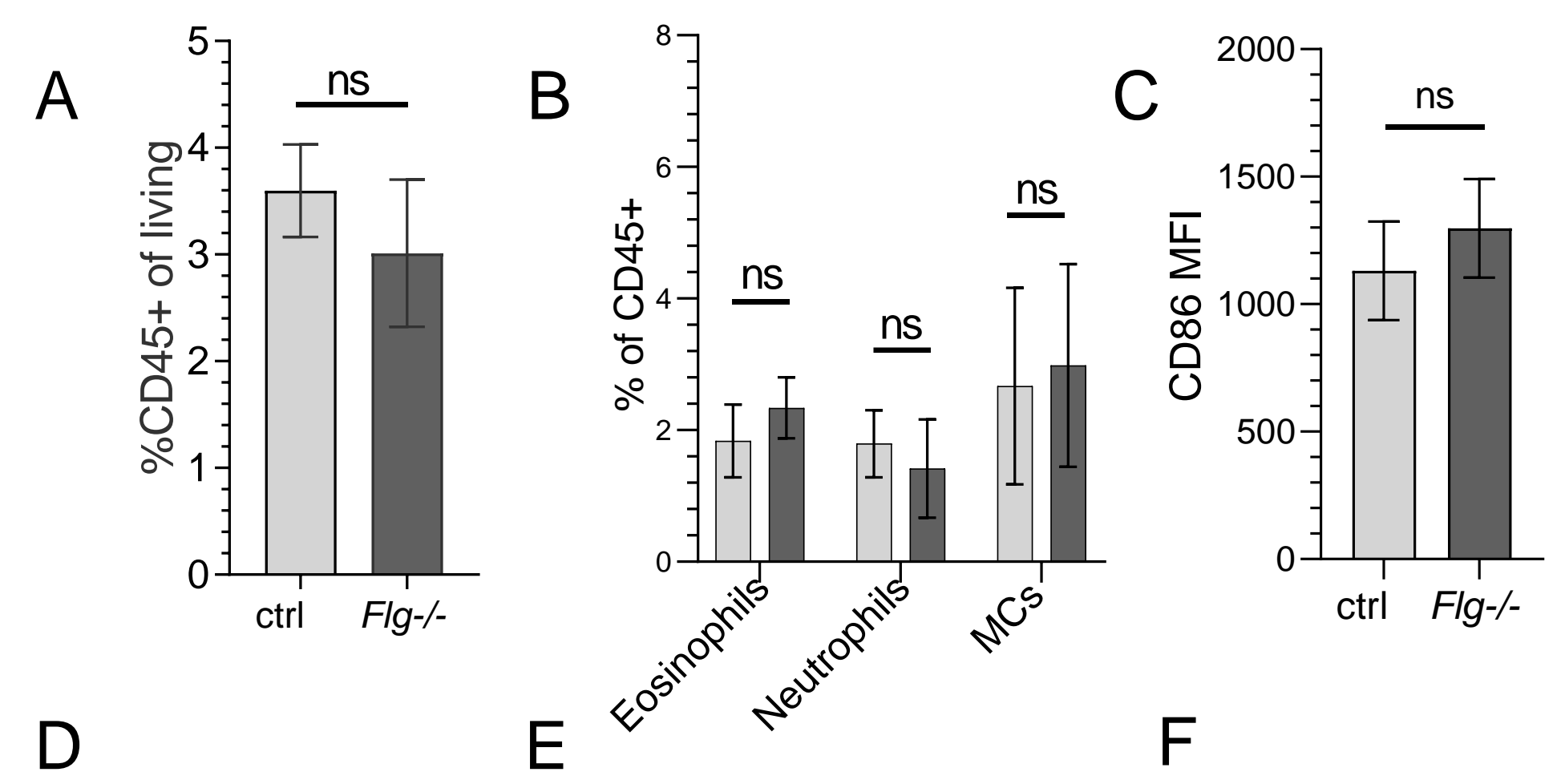

Figure 4
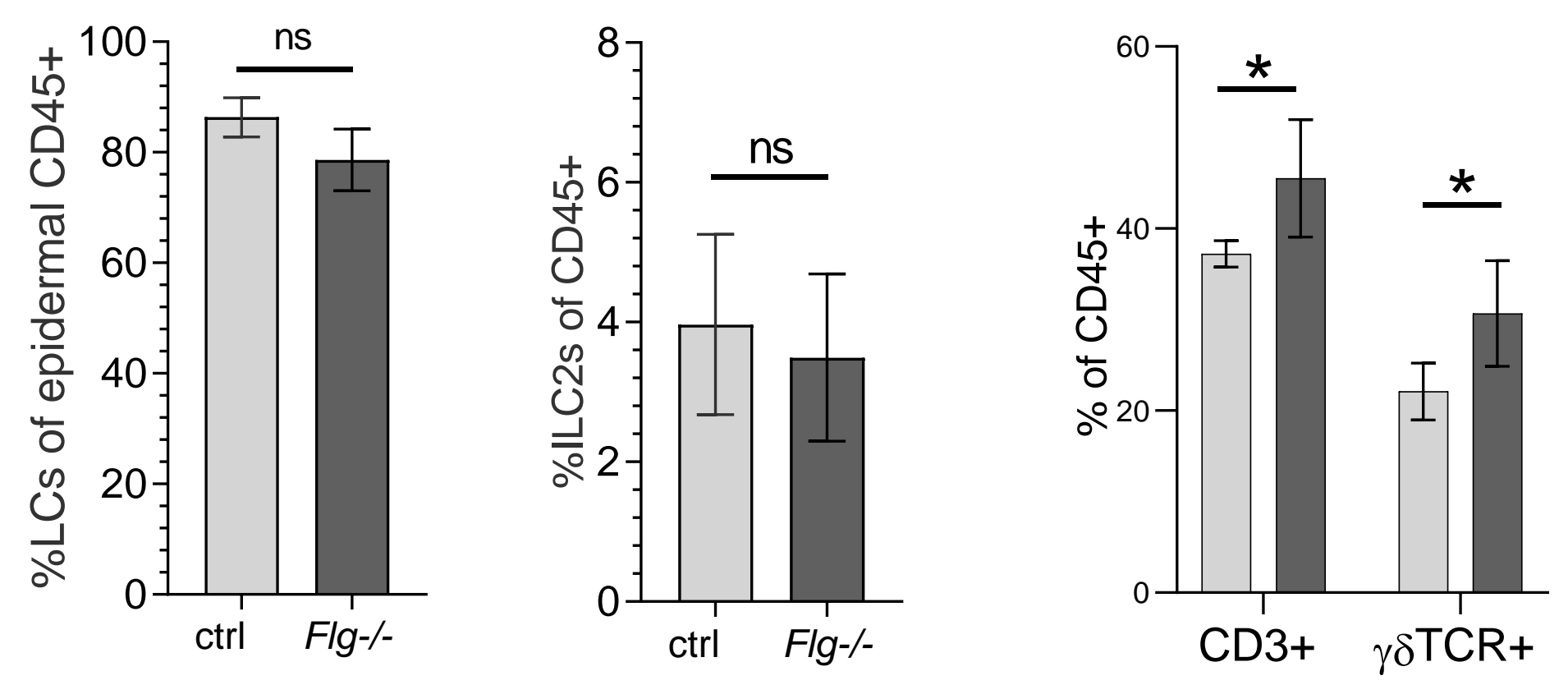
A

B

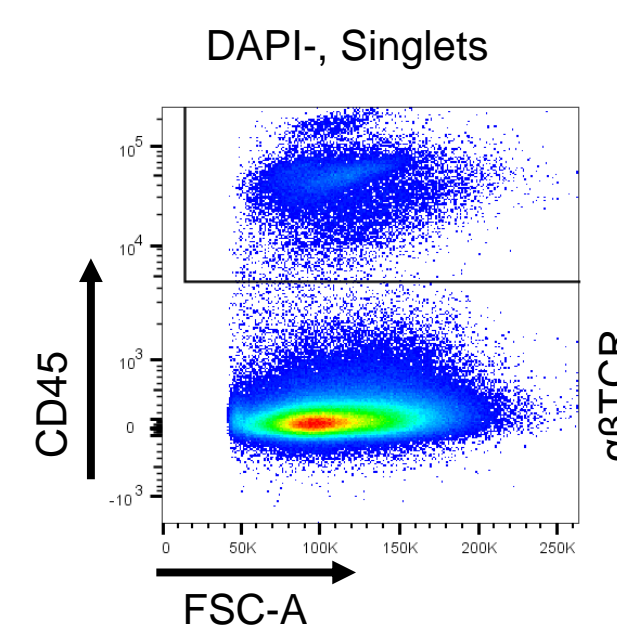

D

CD45+, DAPI-, Singlets

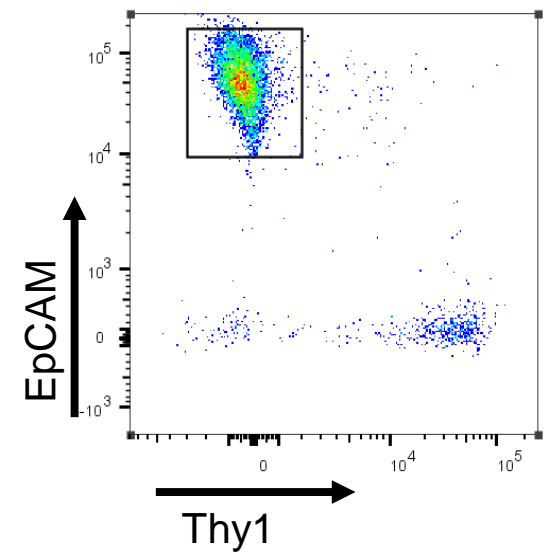

DAPI-, CD45+, Singlets, Lin-, CD4-, CD8-

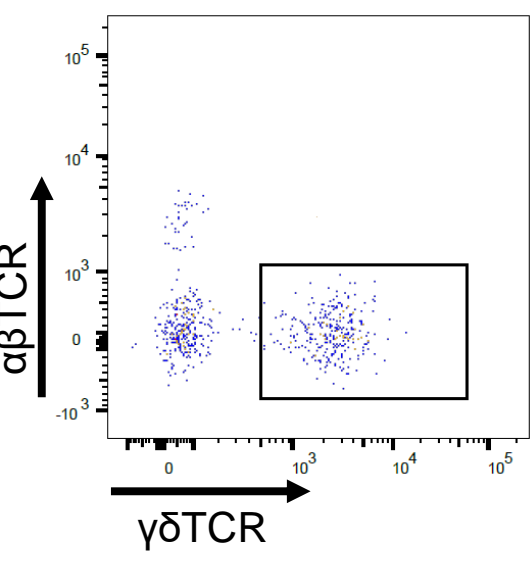

E DAPI-, Singlets, CD45+
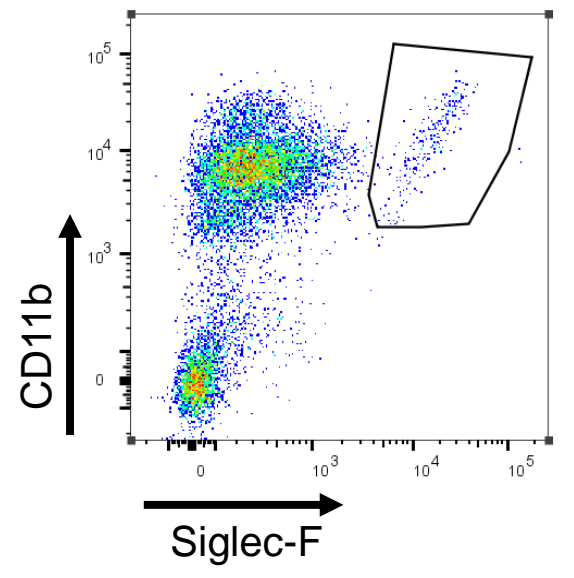

C

DAPI-, Singlets,

CD45+, Lin-, CD3-

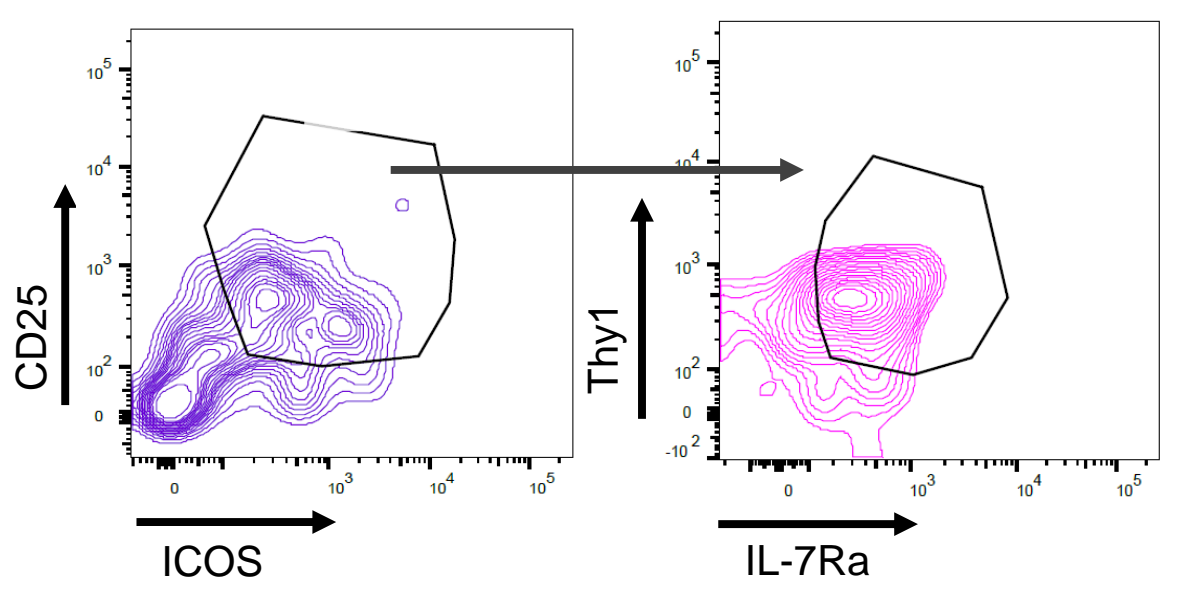

F

DAPI-, Singlets, CD45+

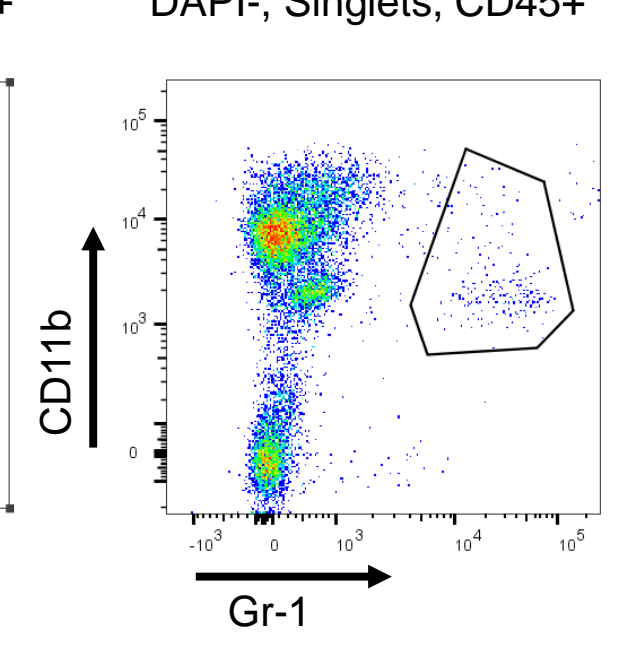

G

DAPI-, Singlets, CD45+, CD11b low

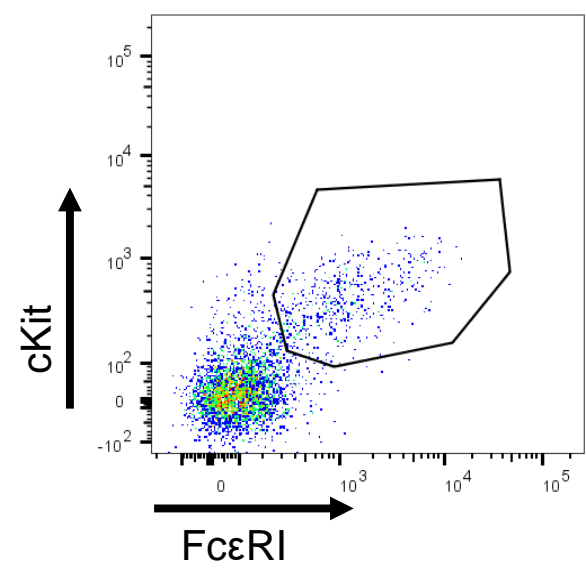

\section{Figure S4}




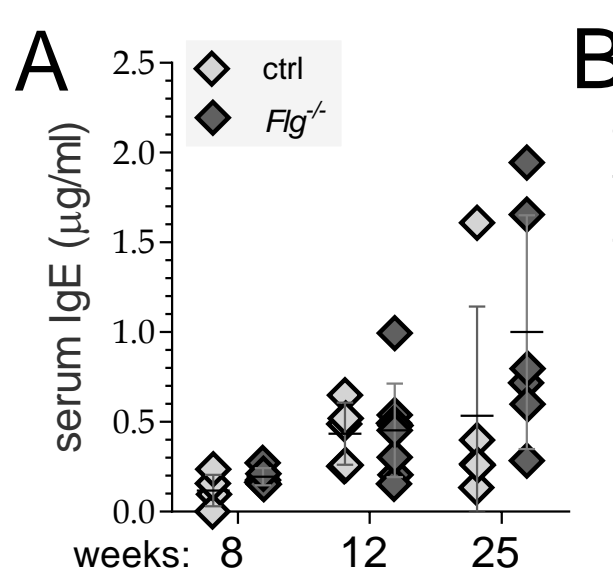

D

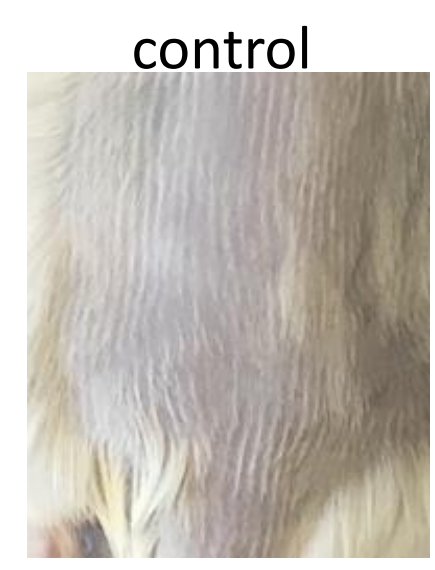

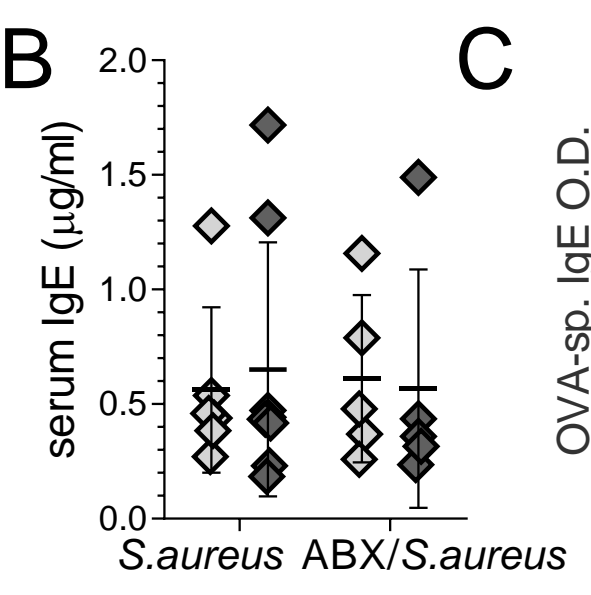

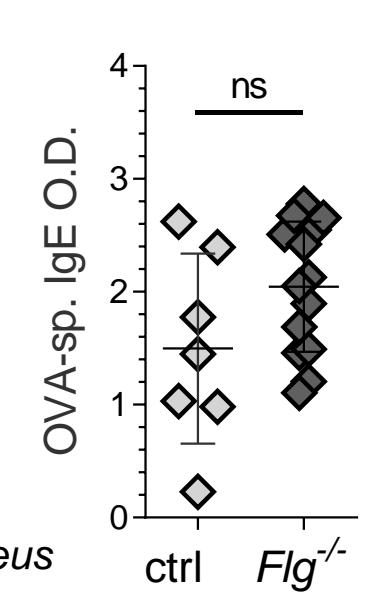

Figure 5
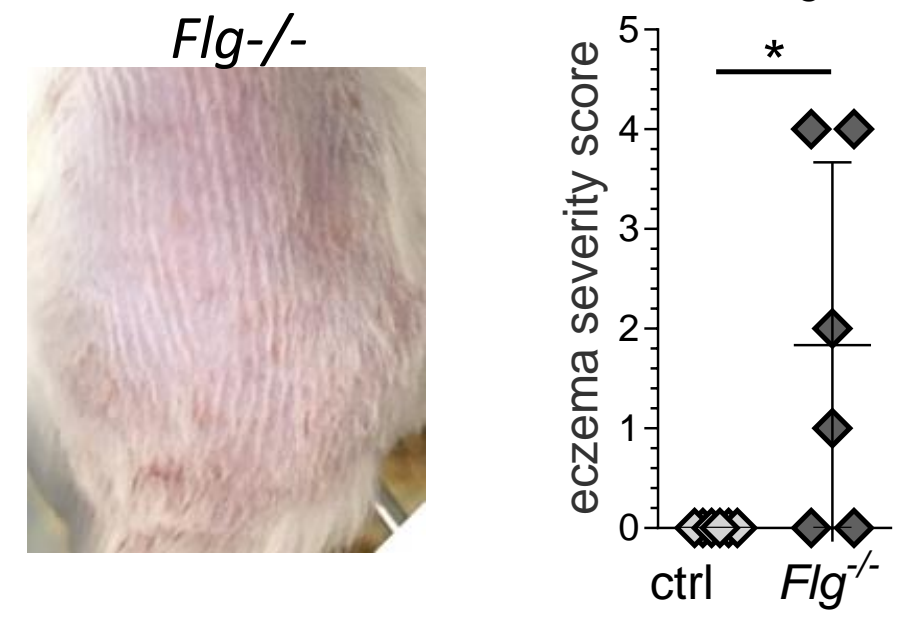

E

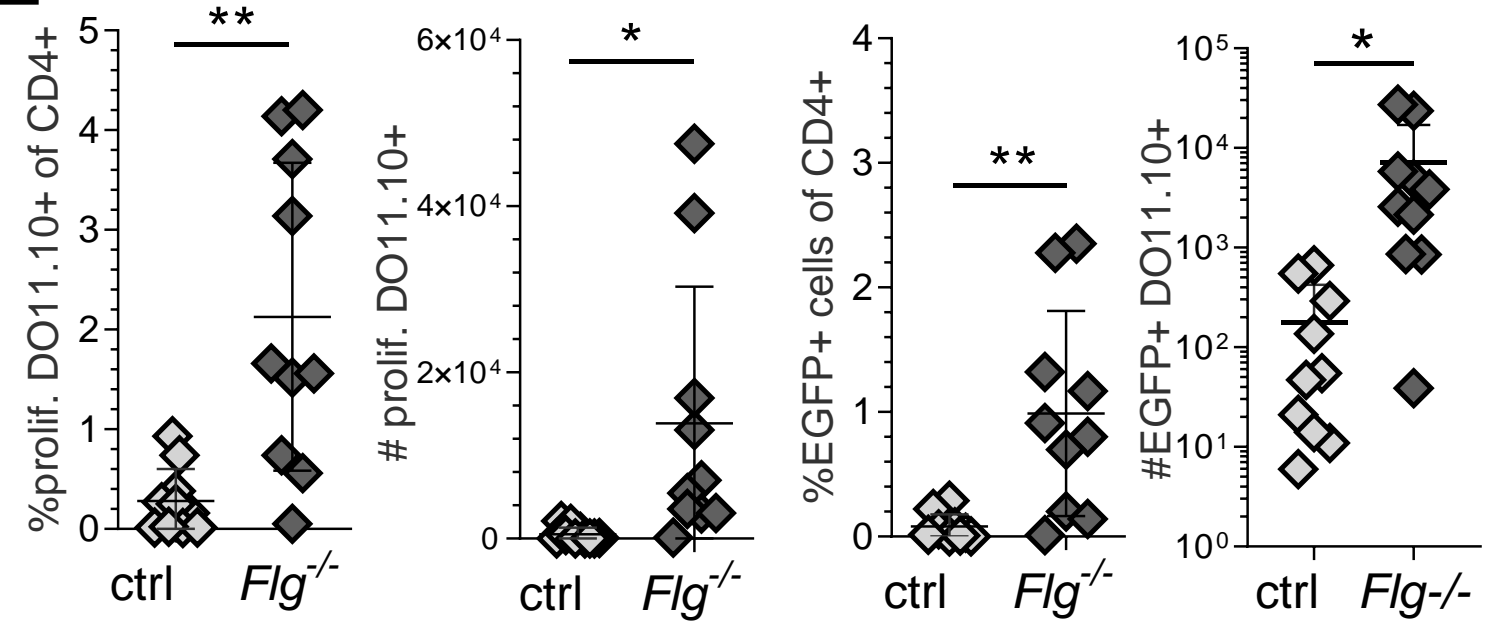


A $\quad$ CD4+DO11.10+

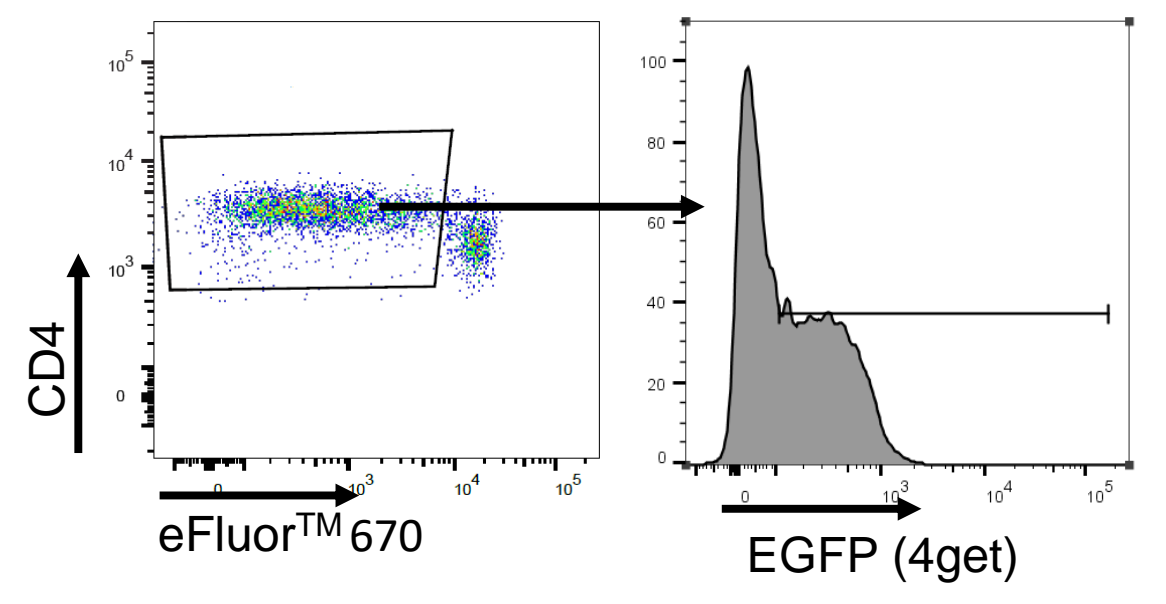

B

\begin{tabular}{|c|l|}
\hline score & criteria \\
\hline 0 & no erythema, no scabbing \\
\hline 1 & mild erythema, no scabbing \\
\hline 2 & erythema, some scabbing \\
\hline 3 & erythema, scabbing over less than $30 \%$ of the back \\
\hline 4 & erythema, scabbing over more than $30 \%$ of the back \\
\hline
\end{tabular}

Figure S5 


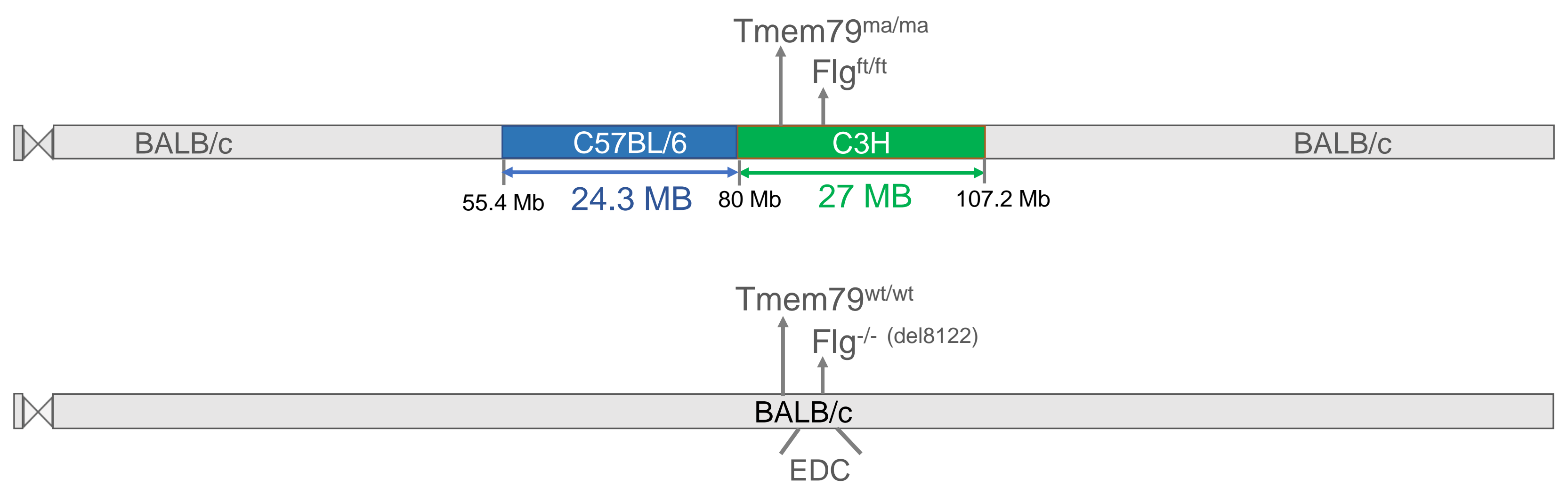

\section{Figure 6}


Potentially damaging

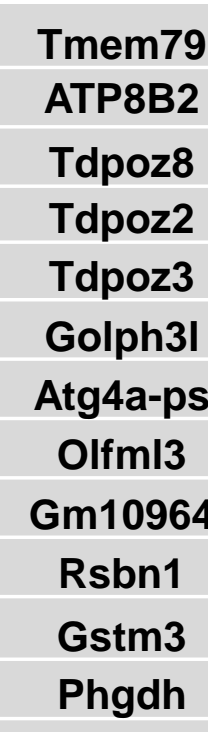

\begin{tabular}{|c|c|}
\hline Lor (x2) & Fga \\
\hline Lelp1 (x2) & Fgb (x2) \\
\hline Sprr2i & Tmem131I (x4) \\
\hline Sprr2k & Lrba (x2) \\
\hline Ivl (x4) & Arnt \\
\hline Lce1b (x2) & Fcgr1 (x3) \\
\hline Lce1a2 (x3) & Polr3c (x2) \\
\hline Lce1c & Trim33 (x4) \\
\hline Lce1d & Ptpn22 \\
\hline Lce1j & Pglyrp3 \\
\hline Kprp & Rorc \\
\hline 2310050 C09Rik & Scamp3 \\
\hline Lce3d & Mtx1 (x2) \\
\hline Lce3f & Muc1 (x4) \\
\hline Lce1m (x2) & Trim46 \\
\hline Crnn (x15) & Dcst2 \\
\hline Flg2 (x26) & Pbxip1 \\
\hline Tchhl1 & Kcnn2 \\
\hline Ecm1 & Atp8b2 \\
\hline Arhgef11 & Nup210l (x8) \\
\hline Ash1l (x4) & Mbnl1 \\
\hline Rab13 & Gatad2b \\
\hline Cgn (x3) & Slc27a3 \\
\hline Magi3 & Npr1 \\
\hline Pear1 & Gm5849 \\
\hline Prcc & Slitr3 \\
\hline Gpatch4 (x2) & Palmd (x2) \\
\hline Naxe & Plrg1 \\
\hline Gm38392 & Gm17359 \\
\hline
\end{tabular}

\begin{tabular}{|c|c|c|}
\hline Dchs2 (x20) & Tuft1 & Kcnd3 \\
\hline Siah2 & Frrs1 & Ddx20 (x3) \\
\hline Gm9774 & Aadacl2fm1 & Tmigd3 (x2) \\
\hline Trmt13 (x3) & Selenbp1 & Ovgp1 (x4) \\
\hline Fhdc1 (x5) & Aadacl2fm2 (x3) & Chil5 \\
\hline Tigd4 (x2) & Ctss (x2) & Dennd2d \\
\hline Fam160a1 (x2) & Hormad1 & Kcna10 (x2) \\
\hline Prss48 (x3) & Adamts 14 & Cym \\
\hline Sh3d19 & Med12l (x2) & Kenc4 \\
\hline Sass6 & $\mathrm{H} 3 \mathrm{c} 14$ & Slc6a17 \\
\hline Dclk2 & Fstl5 (x2) & Gstm6 \\
\hline Lrrc71 & Hjv & Gstm3 \\
\hline Sh2d2a & Map9 (x2) & Celsr2 \\
\hline Rarres1 & Nr1h5 & Fndc7 (x4) \\
\hline Plch1 & Sis $(x 8)$ & Mindy4b-ps \\
\hline Tdpoz8 (x26) & Syt6 & Clrn1 \\
\hline Vmn2r2 & Atg4a-ps (x2) & Rhbg \\
\hline Veph1 (x5) & Olfml3 (x2) & Slc35a3 \\
\hline Gm17402 & Gm10964 & $\mathrm{Agl}(\mathrm{x} 5)$ \\
\hline Tdpoz2 (x3) & Hipk1 & Kpna4 (x2) \\
\hline Tdpoz6 (x5) & Dclre1b (x2) & Arhgef2 (x2) \\
\hline Gm5773 & Ap4b1 (x3) & Rxfp4 (x3) \\
\hline Tdpoz4 (x2) & $\mathrm{Bcl} 2 \mathrm{|l5}$ & Khdc4 (x2) \\
\hline Tdpoz7 & Dhx36 (x2) & Syt11 \\
\hline Spopfm2 & Rsbn1 & Gon4l (x8) \\
\hline Spopfm1 & Aadac & Strit1 \\
\hline Them4 & Lrig2 & Clk2 \\
\hline C2cd4d & Mov10 (x2) & \\
\hline Gucy1a1 & Capza1 & \\
\hline
\end{tabular}

epidermal barrier

immune response 